\title{
Mutual Fund Styles and Clientele-Specific Performance Evaluation
}

\author{
Stéphane Chrétien ${ }^{1} \&$ Manel Kammoun ${ }^{2}$ \\ ${ }^{1}$ IG Wealth Management Chair in Financial Planning and Finance, Insurance and Real Estate Department, Faculty \\ of Business Administration, Laval University, CRREP, GReFA, and LABIFUL, Canada \\ ${ }^{2}$ Département des sciences administratives, Université du Québec en Outaouais, Canada \\ Correspondence: Stéphane Chrétien, Finance, Insurance and Real Estate Department, Faculty of Business \\ Administration, Laval University, 2325, rue de la Terrasse, Quebec City, QC, G1V 0A6, Canada. Tel: \\ 1-418-656-2131, ext. 403380. E-mail: stephane.chretien@ fsa.ulaval.ca
}

Received: November 9, 2019

Accepted: November 27, 2019 Online Published: November 30, 2019

doi:10.5539/ijef.v11n12p89

URL: https://doi.org/10.5539/ijef.v11n12p89

\begin{abstract}
This paper develops clientele-specific performance measures based on the style preferences of mutual fund investors. Proposing an approach that considers investor disagreement and exploits style classification data, we investigate eight measures to represent investors with favorable preferences for size and value equity styles using a large sample of actively-managed U.S. equity mutual funds from 1998 to 2012. We find that the implied style preferences differ in their rational and behavioral features: value and small-cap fund investors (growth and large-cap fund investors) are more (less) averse to difficult economic conditions, and tend to be pessimists and contrarians (optimists and trend followers). The performance of funds assigned to clientele-specific styles becomes neutral or positive when evaluated with measures that consider their most likely style clienteles. The sign of the value added by the industry is ambiguous and depends on the choice of measures. Hence, performance is more favorable when funds are evaluated with their appropriate style-clientele-specific measure, and can otherwise depend on the measure.
\end{abstract}

Keywords: clientele effects, investment styles, mutual funds, performance disagreement, portfolio performance measurement

\section{Introduction}

Since the seminal contributions of Fama and French $(1992,1993$, 1996), size (small-cap versus large-cap) and value (value versus growth) investment styles have grown so much in popularity among investors that equity style investing has become dominant in industry practices. Thousands of mutual funds now advertise themselves according to their size and value focus, often starting with their names. They cater to and attract size and value clienteles who can rely on numerous style classification tools for their investment decisions. This economically significant style differentiation among funds and investors suggests that mutual fund performance evaluation should also differ for size and value clienteles.

The performance evaluation literature does not typically use different measures to evaluate the performance of funds aimed at different clienteles and focuses instead on a unique measure based on a representative investor. The existing evidence, largely based on linear factor models, finds that alpha is somewhat negative, raising questions on the growth of actively managed funds, the skill of active managers and the value added by the industry (e.g., Gruber, 1996; Barras, Scaillet, \& Wermers, 2010; Fama \& French, 2010). Yet there are arguments that such interpretations of traditional alphas are problematic. For example, Berk and Green (2004) and Berk and van Binsbergen (2015) argue that skill is not well measured by traditional alphas, but is instead related to fund size. Ferson and Lin (2014, FL hereafter) find that traditional alphas are not reliable guides to the attractiveness of an investment and show that a client-specific alpha is needed for such a purpose. Assuming incomplete markets and heterogeneous preferences, FL and Chrétien and Kammoun (2017, CK hereafter) finds large and significant performance disagreement in equity funds, documenting that fund values can vary widely across clienteles.

Outlining research challenges, Ferson (2010) emphasizes the importance of identifying meaningful investor clienteles and developing clientele-specific performance measures to evaluate properly mutual funds. In particular, he argues that "in evaluating managed portfolios, one size does not fit all," (p. 229) and that identifying cohorts of investors expected to have similar preferences could lead to a close approximation of the 
correct clientele-specific alpha. While the results of the previously mentioned studies show an important role for clientele-specific performance measures, they provide little evidence on how performance evaluation differs for style clienteles. This paper aims to develop clientele-specific performance measures based on the implied style preferences of equity mutual fund investors and empirically investigates whether performance evaluation differs for size and value clienteles. Our approach has two distinctive features.

First, we propose a performance framework with investor disagreement that allows for the identification of meaningful stochastic discount factors (SDFs) for style clienteles. The framework is based on the SDF alpha approach of Chen and Knez (1996) and is a refinement of the best clientele approach of CK. The performance measures are extracted from a set of SDFs admissible under the law-of-one-price and no-good-deal conditions, an incomplete market setup initiated by Cochrane and Saá-Requejo (2000). Our identification strategy uses the empirical results of FL on the magnitude of investor disagreement and assumes that style portfolios are representative investments for style clienteles. This framework ensures that the performance measures correctly price passive portfolios and generates a realistic and sufficiently large disagreement to differentiate the style clienteles.

Second, we introduce a method to exploit available style classification data in the CRSP mutual fund database better. The method focuses on Lipper objective codes as they cover the most relevant period and facilitate the classification of funds into size and value styles. It also accounts for code changes and missing codes by using a threshold for style inclusion that considers whether a fund has been assigned to a code for enough time. The method is thus based on public information from a leading industry provider that investors could presumably consult to form their investment decisions, considers the stability of the code data, and avoid the ad hoc attribution of codes into style categories. Using the method, we classify the funds and their clienteles into four general styles (small-cap, large-cap, value and growth) and four specific styles (large-cap growth, small-cap growth, large-cap value and small-cap value).

Beyond the predominance of style investing in industry, there are many arguments for size and value styles to be most relevant for identifying meaningful investor clienteles (Note 1). Barberis and Shleifer (2003) discuss the interest of financial service firms to understand style preferences and there is a large literature that studies the economic differences between style investors (Note 2). From a rational perspective, this literature argues that style investors have different endowments, risk aversion and investment horizons, which lead them to different exposures to priced state variables that capture risks related to, among others, labor income, macroeconomic conditions, long-run consumption and displacement (e.g., Fama \& French 1996; Jagannathan \& Wang 1996; Liew \& Vassalou 2000; Bansal \& Yaron 2004; Gârleanu, Kogan, \& Panageas 2012; etc.), or different intertemporal hedging demands (Lynch 2001; Jurek \& Viceira 2011). From a behavioral perspective, Lakonishok, Shleifer, and Vishny (1994); Shefrin and Statman (1995, 2003); La Porta (1996); La Porta, Lakonishok, Shleifer, and Vishny (1997); Piotroski and So (2012); Blackburn, Goetzmann, and Ukhov (2014); Shefrin (2015) and Walkshausl (2017) argue that style investors have different judgments, sentiment sensitivities and trading patterns. In general, they find that value and small-cap investors tend to be pessimists and contrarians, while growth and large-cap investors tend to be optimists and trend followers (Note 3).

Recently, using detailed data on Swedish residents, Cronqvist, Siegel, and Yu (2015) and Betermier, Calvet, and Sodini (2017) examine the biological basis, household characteristics, life experiences and hedging motives of value and growth investors. They find that style preferences are partially ingrained from birth, but also develop from life experiences. Consistent with rational arguments about risk exposures and hedging demands, they document that value investors tend to have higher wealth, lower human capital, lower macroeconomic risk and lower investment horizon than growth investors. But in support with behavioral arguments about pessimism, they show that value investors grew up with lower socioeconomic status parents had more past adverse macroeconomic experiences and are less attracted to speculative, lottery-type, stocks than growth investors. Finally, they outline the dynamic nature of style preferences over the life cycle, with a shift from growth to value as investors become older and financially healthier.

Empirically, this paper is the first to focus on a performance evaluation that accounts for the heterogeneity of size and value clienteles. Using a sample of 2530 actively-managed open-ended U.S. equity mutual funds with monthly returns from 1998 to 2012, our investigation makes three contributions. First, we show that the SDFs identified by our approach are relevant by studying their economic properties. The results suggest that value and (to a lesser extent) small-cap fund investors are more averse to difficult economic conditions, and tend to be pessimists and contrarians. Growth and large-cap fund investors tend to be optimists and trend followers. Hence, the SDFs are different enough to generate performance disagreement and have rational and behavioral features that are generally consistent with existing studies on size and value investors. 
Second, we implement a clientele-specific evaluation using the style SDFs. We find that the funds assigned to size and value styles have neutral to positive average alphas when evaluated with measures that consider their most likely style clienteles. Hence, when the evaluation considers relevant clienteles, fund performance is more positive than existing evidence typically shows. The performance of the other funds is sensitive to the clienteles. Specifically, their average alphas are significantly negative to neutral for value and small-cap clienteles, but neutral to significantly positive for growth and large-cap clienteles. For these funds, the different rational and behavioral features of the style SDFs are important determinants of performance evaluation.

Third, we document the value added of the mutual fund industry from the perspective of different style clienteles. Given that funds are attributed multiple performance values by the SDFs, we examine many cross-sectional performance distributions by considering either the minimum or maximum alpha of each fund. The results show that the sign of the value added is ambiguous and depends on the choice of measures. But they suggest that the value added is greater for growth and large-cap investors than for value and small-cap investors, although the difference is sensitive to the magnitude of disagreement allowed in our performance framework.

Overall, this paper develops an approach to identify relevant clientele-specific SDFs and achieve a clientele-specific evaluation. Empirically, it suggests a significant role for equity styles because implied preferences and alphas differ for size and value mutual fund clienteles. In contrast to the negative results of many existing studies using a single measure based on a representative investor, it finds that performance is more positive when funds are evaluated with their related style-clientele-specific measure, and can otherwise depend on the measure. It is an important first step toward confirming the conjecture of Ferson (2010) that clientele-specific measures based on meaningful clienteles might be necessary to evaluate properly managed funds.

\section{Performance Measures for Style Clienteles: Theoretical Framework}

This section develops a framework for performance evaluation under the assumption that there are style clienteles. First, we present a basic setup for evaluation with investor disagreement. Second, we describe our strategy for identifying meaningful SDFs for style clienteles. Third, we propose style-clientele-specific measures for the evaluation of individual mutual funds. Fourth, we provide a discussion to highlight the distinctive features of the approach.

\subsection{Performance Evaluation with Investor Disagreement}

This paper exploits the general framework of the SDF performance approach, first proposed by Glosten and Jagannathan (1994) and Chen and Knez (1996), to allow for investor disagreement that occurs when an investor evaluates a fund differently from another investor (see Ahn, Cao \& Chrétien, 2009, FL and CK). In this approach, the performance, or SDF alpha, is defined from the following equation:

$$
\alpha_{M F}=E\left[m R_{M F}\right]-1
$$

where $m$ is the SDF of an investor interested in valuing an individual mutual fund with gross return $R_{M F}$. Unlike most of the literature, this paper does not assume that there is a unique SDF for all investors. Instead, we view a fund investor's SDF as part of a set $M$ of admissible SDFs that allow for investor disagreement and heterogeneous preferences.

Under general conditions, in an incomplete market, Chen and Knez (1996) show that there is an infinite number of admissible SDFs that generates a potentially infinite alpha disagreement between investors. To restrict SDFs in an economically meaningful way, we follow Hansen and Jagannathan (1991), Cochrane and Saá-Requejo (2000) and CK to impose two conditions: the law-of-one-price and no-good-deal conditions. The law-of-one-price condition assumes that fund investors give zero performance to passive portfolios. The no-good-deal condition assumes that fund investors do not allow investment opportunities that have too large Sharpe ratios. These restrictions are equivalent to limiting the variability of SDFs. Specifically, Cochrane and Saá-Requejo (2000) show that, under these two conditions, for all $m \in M$, the SDF standard deviation is bounded as follows:

$$
\frac{h^{*}}{R_{F}} \leq \sigma(m) \leq \frac{\bar{h}}{R_{F}}
$$

where $h^{*}$ is the optimal Sharpe ratio attainable from the passive portfolios, $\bar{h}$ is the maximum allowable Sharpe ratio for investments not considered good deals and $R_{F}$ is the risk-free return. Intuitively, we can interpret the SDFs as representing the marginal preferences of mutual fund investors. Equation (2) stipulates that the variability of their marginal utilities should be large enough to correctly price existing passive portfolios, but small enough to rule out implausibly high risk aversion that would allow good deals to be viable.

The SDFs admissible under these conditions are advantageous for performance evaluation for two reasons. First, they do not suffer from the benchmark choice problem that occurs when a selected benchmark does not correctly 
price passive portfolios (Chen \& Knez, 1996; Ahn et al., 2009). Second, they allow for a reasonable disagreement consistent with FL. Specifically, as the set $M$ of SDFs is closed and convex, there is a finite alpha disagreement between investors because it is possible to find lower and upper performance bounds:

$$
\underline{\alpha}_{M F} \leq \alpha_{M F} \leq \bar{\alpha}_{M F},
$$

CK call these bounds the worst and best clientele alphas, respectively. Using equity mutual funds, they document disagreement values comparable to those of FL and significant enough to change the value of funds from negative to positive, depending on the clienteles. Their results confirm the importance of investor disagreement and clientele effects in performance evaluation.

\subsection{Stochastic Discount Factors for Style Clienteles}

Instead of focusing on fund-specific clienteles, like a fund's best and worst clienteles, this paper examines the general clienteles interested in particular investment styles within the mutual fund industry. This section provides a strategy for selecting specific SDFs in $M$ that identifies these style clienteles. Specifically, this paper assumes that grouping funds by their investment style is a relevant strategy for identifying meaningful investor clienteles. Let $R_{S}$ be the return on a portfolio of funds grouped according to their similar style $s$. For simplicity, let $S$ be the set of styles under consideration (i.e., $S=$ \{Value, Growth, etc. $\}$ ) as well as the total number of styles. Using any $m \in M$, we can measure the performance, or alpha, of this style portfolio by:

$$
\alpha_{s}=E\left[m R_{s}\right]-1 .
$$

Given the existence of many admissible SDFs, investors likely disagree on this alpha. Our approach stipulates that the SDF at the upper performance bound is a meaningful SDF for representing the clienteles favorable to the style. Specifically, to find the SDF for clienteles most favorable to the investment style providing a return $R_{S}$, we solve the following problem:

$$
\begin{gathered}
\bar{\alpha}_{s}=\sup _{m \in M} E\left[m R_{s}\right]-1, \\
\text { subject to } E\left[m \mathrm{R}_{\mathrm{K}}\right]=1, E\left[m^{2}\right] \leq \frac{\left(1+\bar{h}^{2}\right)}{R_{F}{ }^{2}},
\end{gathered}
$$

where $E\left[m \mathrm{R}_{\mathrm{K}}\right]=1$ is law-of-one-price condition, with $\mathrm{R}_{\mathrm{K}}$ being a vector of returns on $K$ passive portfolios and 1 is a $K \times 1$ unit vector, and $E\left[m^{2}\right] \leq \frac{\left(1+\bar{h}^{2}\right)}{R_{F}^{2}}$ is the no-good-deal condition, with $\bar{h}$ being the maximum Sharpe ratio allowed. Cochrane and Saá-Requejo (2000) demonstrate that this problem has the following closed-form solution:

$$
\bar{\alpha}_{s}=E\left[\bar{m}_{s} R_{s}\right]-1,
$$

with:

$$
\begin{gathered}
\bar{m}_{s}=m_{L O P}+v_{s} w_{s}, \\
m_{L O P}=\mathrm{a}^{\prime} \mathrm{R}_{\mathrm{K}}, \\
w_{s}=R_{s}-\mathrm{c}_{\mathrm{s}}{ }^{\prime} \mathrm{R}_{\mathrm{K}},
\end{gathered}
$$

where:

$$
\begin{gathered}
\mathrm{a}^{\prime}=1^{\prime} E\left[\mathrm{R}_{\mathrm{K}} \mathrm{R}_{\mathrm{K}}^{\prime}\right]^{-1}, \\
\mathrm{c}_{\mathrm{S}}{ }^{\prime}=E\left[R_{S} \mathrm{R}_{\mathrm{K}}^{\prime}\right] E\left[\mathrm{R}_{\mathrm{K}} \mathrm{R}_{\mathrm{K}}^{\prime}\right]^{-1}, \\
v_{S}=\sqrt{\frac{\left(\frac{\left(1+\bar{h}^{2}\right)}{R_{F}^{2}}-E\left[m_{L O P}^{2}\right]\right)}{E\left[w_{S}^{2}\right]} .}
\end{gathered}
$$

In this solution, $\bar{\alpha}_{s}$ is the upper bound on the (expected) alpha of a style portfolio, i.e., the highest average performance value found from the heterogeneous investors with SDFs in the set $M$. The SDF that solves the problem is denoted by $\bar{m}_{s}$ and called the "(clientele-specific) style SDF" for investment style $s$. It identifies the SDF for the class of investors most favorable to style $s$ and hence provides a way to obtain meaningful SDFs for various style clienteles. Its first component, $m_{L O P}$, is shown by Hansen and Jagannathan (1991) to be the minimum volatility SDF under the law-of-one-price condition and used by Chen and Knez (1996) for their LOP performance measure. As indicated by the notation, it is common to all style SDFs because it depends only on passive portfolio returns and does not vary with the style portfolio investigated. 
Its second component, $v_{s} w_{s}$, is a clientele-specific component that accounts for investor disagreement. The replicating error term $w_{S}$ is the difference between the style portfolio return and the best replicating payoff constructed from the passive portfolio returns. The disagreement parameter $v_{s}$ accounts for the no-good-deal restriction and is a function of the maximum Sharpe ratio $\bar{h}$. The second component thus indicates that investors mostly agree on the evaluation of style portfolios that have easy-to-replicate returns or when they consider most allowable investment opportunities as good deals. In other instances, there can be significant clientele effects in performance evaluation.

\subsection{Style-Clientele-Specific Performance Evaluation}

The previous section provides a strategy to identify meaningful SDFs for style clienteles. Assuming that $S$ representative style portfolios can be formed, the strategy yields $S$ different clientele-specific style SDFs, i.e., $\bar{m}_{s}$ for all $s \in S$. This section describes how these SDFs can be used in a style-clientele-specific performance evaluation.

The evaluation necessitates that we distinguish between two types of individual mutual funds. The first type includes funds assigned to clientele-specific investment styles. Performance measurement for these funds is relatively straightforward because we can use their associated style SDFs. Let $R_{M F, S}$ be the return on a fund assigned to clientele-specific style $s$. Its unique style-clientele-specific alpha is given by:

$$
\alpha_{M F, S}=E\left[\bar{m}_{S} R_{M F, S}\right]-1 \text {. }
$$

The second type includes funds not assigned to clientele-specific styles. Such funds could have a style different from the ones considered, frequent changes of styles through time or missing style classification information. Because it is not possible to select a unique style SDF for these funds, we instead examine their performance for all style clienteles. Let $R_{M F,-}$ be the return on a fund not assigned to a clientele-specific style. Its multiple style-clientele-specific alphas are given by:

$$
\alpha_{M F, s}=E\left[\bar{m}_{S} R_{M F,-}\right]-1, \text { for all } s \in S .
$$

Equations (14) and (15) simply specify how we evaluate the performance of individual funds using the style-clientele-specific performance measures. When a fund can be clearly related to a style, it likely caters to and attracts the clienteles most favorable to its style. It then makes sense to use the style SDF associated with its style for performance measurement. Even though this SDF implies preferences that are favorable to the style of the fund, it can still evaluate the fund positively or negatively, depending on how the fund differs from the style portfolio that includes other funds of similar style. However, when a fund cannot be clearly related to a style, it could presumably cater to and attract all types of clienteles. Our measures examine if the fund provides added value to the different style clienteles who are prevalent in practice. Furthermore, by considering all the style-clientele-specific measures for evaluation, we can account for the disagreement between the style clienteles on the value of this fund.

\subsection{Discussion}

It is important to distinguish the approach used in this paper from those of its two most related articles. In FL and CK, the approaches lead to the evaluation of fund-specific performance bounds, which identify the most extreme alphas for each fund. In particular, although CK show the relevancy of the set $M$ of admissible SDFs used in this study, they only focus on the performance for the best and worst clienteles of each fund. Such clienteles are likely to be "niche" clienteles that like or dislike all the characteristics that a fund has to offer. Instead of focusing on these niche clienteles, this paper examines general style clienteles within the fund industry. Hence it studies the performance from different SDFs than CK, a choice with implications as large as evaluating alpha with the Fama-French model instead of the CAPM (or any other models), which implicitly assumes different preferences for the representative investor.

Understanding this distinction is helpful to interpret correctly the style-clientele-specific performance evaluation in this paper. In particular, unless one is willing to make an additional assumption that all existing clienteles are identified by the selected styles, it is not true that the style SDFs are appropriate to evaluate the performance for all investors, even for a particular style. For example, if a negative alpha is found for a growth fund with the growth SDF, this would be useful information for growth investors in general, as the fund fails to provide them added value. Yet it is possible that this fund provides a positive value to a niche clientele (e.g., growth investors with favorable preferences for other fund characteristics, like liquidity, tax efficiency, etc.), and hence has a positive best clientele alpha. Furthermore, within each style, it is not the case that a simple averaging of the SDF alphas from an alternative approach (like the CAPM, Fama-French or best clientele alphas) provides the same information as the average style-clientele-specific alphas. For example, the average CAPM alpha or best clientele alpha for all growth funds provide the mean value of the growth fund sector for either a quadratic utility 
representative investor or the most favorable niche clienteles of each fund in the sector. This value is likely different from the value of the sector for growth investors in general.

As emphasized in the introduction, focusing on style clienteles instead of representative investors or extreme clienteles is relevant for two main reasons. First, as argued by Ferson (2010), identifying cohorts of investors who could have similar preferences could lead to an evaluation of a clientele-specific alpha. Our approach allows the estimation of meaningful style-specific SDFs and provides a performance evaluation relevant for style investors. Most of the literature focuses instead on an evaluation based on representative investors, which ignores investor disagreement and different cohorts of investors. Second, style investors are commonly-studied clienteles with documented significance in practice and academia. It is difficult to assess the importance of the niche clienteles implicitly studied by FL and CK, but an evaluation specific to style investors is likely more relevant as their importance has been well established.

\section{Methodology and Data}

\subsection{Methodology}

The style SDF has an analytical solution that has $2 K+1$ parameters to estimate, where $K$ is the number of passive portfolios. We use the generalized method of moments (GMM) of Hansen (1982) for estimation and inferences. For a sample of $T$ observations, we rely on a just-identified system with the following moments:

$$
\begin{gathered}
\frac{1}{T} \sum_{t=1}^{T}\left[\left(\mathrm{a}^{\prime} \mathrm{R}_{\mathrm{Kt}}\right) \mathrm{R}_{\mathrm{Kt}}\right]-1=0, \\
\frac{1}{T} \sum_{t=1}^{T}\left[\left(R_{s t}-\mathrm{c}_{s}{ }^{\prime} \mathrm{R}_{\mathrm{Kt}}\right) \mathrm{R}_{\mathrm{Kt}}\right]=0 \\
\frac{1}{T} \sum_{t=1}^{T}\left[\left(\mathrm{a}^{\prime} \mathrm{R}_{\mathrm{Kt}}+v_{s}\left(R_{s t}-\mathrm{c}_{s}{ }^{\prime} \mathrm{R}_{\mathrm{Kt}}\right)\right) R_{s t}\right]-1-\bar{\alpha}_{s}=0 .
\end{gathered}
$$

Equation (16) uses the fundamental SDF pricing equation to set the $K$ moments needed to correctly price the $K$ passive portfolios, estimating the $K \times 1$ vector of coefficients a. It allows the estimation of the LOP SDF of Chen and Knez (1996), $m_{L O P t}=\mathrm{a}^{\prime} \mathrm{R}_{\mathrm{Kt}}$. Equation (17) specifies the $K$ orthogonality conditions between the replication error term, $w_{s t}=R_{s t}-\mathrm{c}_{s}{ }^{\prime} \mathrm{R}_{\mathrm{Kt}}$, and passive portfolio returns. They estimate the linear combination of passive portfolio returns that best replicates the style portfolio return, estimating the $K \times 1$ vector of coefficients c. The moment in equation (18) allows the estimation of the disagreement parameter $v_{s}$, which completes the estimation of the style SDF $\bar{m}_{s t}=\mathrm{a}^{\prime} \mathrm{R}_{\mathrm{Kt}}+v_{s}\left(R_{s t}-\mathrm{c}_{s}{ }^{\prime} \mathrm{R}_{\mathrm{Kt}}\right)$. The estimation of $v_{s}$ implements an empirical version of equation (7) and requires an exogenously specified value for $\bar{\alpha}_{s}$, the expected alpha for clienteles most favorable to the style.

To evaluate the performance of funds with the style SDF, we add the following moment to the previous system:

$$
\frac{1}{T} \sum_{t=1}^{T}\left[\bar{m}_{s t} R_{M F t}\right]-1-\alpha_{M F, s}=0,
$$

where the fund return $R_{M F t}$ represents the return on a fund assigned to a style, $R_{M F, s t}$, or the return on a fund not assigned to a style, $R_{M F,-t}$. This moment represents the empirical counterpart of the style-clientele-specific performance measures proposed in this paper.

Our procedure estimates alpha separately for each fund. Farnsworth, Ferson, Jackson, and Todd (2002) demonstrate that estimating a system for one fund at a time produces the same point estimates and standard errors for alpha as a system that includes an arbitrary number of funds. Also, the estimates are not influenced by the choice of the weighting matrix in GMM because the systems are just identified. Their statistical significance is assessed with the asymptotic properties derived by Hansen (1982), with standard errors adjusted for conditional heteroskedasticity and serial correlation using the method of Newey and West (1987) with two lags (Note 4).

Empirically, this paper investigates the style clienteles and performance of actively-managed U.S. equity mutual funds. The estimation of the previous system requires three important methodological choices in relation to these funds. The first choice is the style classification of funds and the formation of style portfolios. Section 4 examines this choice carefully and introduces an approach to exploit available style classification data in the CRSP Survivor-Bias-Free US Mutual Fund Database better. It shows that the resulting style classifications and portfolios, defined by size and value sorts, are relevant for our methodology. We next discuss the second and third choices: the value of the upper performance bound on the style portfolio return, $\bar{\alpha}_{s}$, and the assets needed to form the passive portfolio returns $R_{K}$.

As discussed previously, the estimation of $v_{S}$ with equation (18) necessitates a pre-specified value of $\bar{\alpha}_{S}$. This value should be a realistic alpha for clienteles attracted to the style, because it ultimately identifies the SDF meant to capture the marginal preferences of the class of investors most favorable to the style. FL provide an indirect way 
to select a relevant value and we exploit their results. They study the effects of investor disagreement on performance evaluation and estimate bounds for the expected disagreement with a traditional alpha for various benchmark returns. For example, using the factors of Fama and French (1993) and a sample of funds similar to ours, they find mean and median monthly bound values of $0.248 \%$ and $0.212 \%$, respectively (see their table 3 , panel A). Hence, their results imply that clienteles most favorable to a style could realistically expect mean and median alphas of $\alpha_{S, F F}+0.248 \%$ and $\alpha_{S, F F}+0.212 \%$, respectively, where $\alpha_{S, F F}$ is the Fama-French alpha (Note 5).

In section 4.3 , we use these results to fix the value of $\bar{\alpha}_{s}$. Specifically, we estimate the Fama-French alpha for each style portfolio and add the just mentioned mean and median bound estimates to compute realistic values of alphas for favorable clienteles. Based on these values, we select an economically relevant value for $\bar{\alpha}_{s}$. Although this value represents our main choice, we also empirically examine the effects on the results of other sensible values in section 5.4. This method for estimating $v_{s}$ differs from the method used by Cochrane and Saá-Requejo (2000), CK and Chrétien and Kammoun (2018). These papers estimate $v_{s}$ by relying on exogenous values for the maximum Sharpe ratio $\bar{h}$. CK find that their alpha estimates are sensitive to the choice of $\bar{h}$, although their conclusions hold for all reasonable values. This paper avoids the specification of a maximum Sharpe ratio and instead uses available evidence on disagreement to choose a relevant alpha for clienteles favorable to a style.

The third important methodological choice is the selection of passive portfolios. These portfolios are central to $m_{L O P}$, the part of $\bar{m}_{S}$ common to all style clienteles. In our setup, no investor disagrees on their value. We choose a risk-free asset and ten industry portfolios and details on the specific return series are provided in the data section. The inclusion of the risk-free asset controls for cash positions in equity funds and follows the advice of Dahlquist and Söderland (1999) to fix the mean of the SDFs to a reasonable value. Industry portfolios are widely used as basis assets in asset pricing, and categorization by industry is a common practice for mutual fund investors and researchers. For the purpose of this study, selecting industry portfolios instead of size and value portfolios also provides a crucial benefit: it facilitates the identification of style SDFs that, because they generate disagreement on the value of the style portfolios, are more likely to meaningfully represent different style clienteles. It is thus useful to exclude portfolios formed on criteria related to the investigated styles from the set of passive portfolios to avoid obtaining SDFs that lead to no disagreement on them (Note 6).

Finally, we summarize the empirical results by using numerous statistics. First, we show the mean, standard deviation and selected percentiles of the distributions of estimated alphas and their $t$-statistics, computed as $t=\hat{\alpha} / \hat{\sigma}_{\widehat{\alpha}}$, where $\hat{\alpha}$ is the estimated alpha and $\hat{\sigma}_{\widehat{\alpha}}$ is its Newey-West standard error. We also provide $t$-statistics to test the hypothesis that the cross-sectional mean of estimated alphas is equal to zero. This test assumes that the distribution of alphas across funds is multivariate normal with a zero mean, a standard deviation equal to the observed cross-sectional standard deviation, and a correlation between any two alphas of 0.044 . This value corresponds to the cross-sectional dependence in performance among equity funds, adjusted for data overlap, provided in Barras et al. (2010, p. 193) and Ferson and Chen (2015, appendix, p. 62). Second, we present proportions of estimated alphas that are positive and negative.

\subsection{Data}

Our fund data consist of monthly net-of-fee returns on actively-managed open-ended U.S. equity mutual funds from January 1998 to December 2012. The data source is the CRSP Survivor-Bias Free Mutual Fund US Database and our starting date corresponds to the date of first availability of Lipper codes, which are central to the style classification approach introduced in section 4. Following Kacperczyk, Sialm, and Zheng (2008), we exclude bond funds, balanced funds, money market funds, international funds, funds that are not strongly invested in common stocks, index funds and funds not opened to investors (Note 7).

Our sample selection also mitigates numerous biases documented in the literature. Survivorship bias is treated in the CRSP database. Selection bias does not matter for our study period, as Elton, Gruber, and Blake (2001) and Fama and French (2010) show its presence only before 1984. To deal with back-fill and incubation biases, we follow Elton et al. (2001), Kacperczyk et al. (2008) and Evans (2010). We eliminate observations before the organization date of the funds, funds with no reported organization date and funds without a name, since they tend to correspond to incubated funds. We also exclude funds with total net assets below $\$ 15$ million in the first year of entering the database. As a last sampling choice, following Barras et al. (2010) and others, we impose a minimum fund return requirement of 60 months. While this screen introduces a weak survivorship bias, it is useful to obtain reliable statistical estimates with GMM (Note 8). We obtain a final sample of 2530 actively-managed open-ended U.S. equity mutual funds.

The passive portfolio returns are the monthly returns on the one-month U.S. Treasury bills (taken from CRSP) and 
ten industry portfolios (taken from Kenneth R. French's website). The industries are consumer nondurables (NoDur), consumer durables (Durbl), manufacturing (Manuf), energy (Enrgy), high technology (HiTec), telecommunication (Telcm), shops (Shops), healthcare (Hlth), utilities (Utils) and other sectors (Others).

Table 1 presents summary statistics for the monthly returns of the mutual funds (panel A) and passive portfolios (panel B). Panel A also includes summary statistics for the Fama-French SDF alphas with their corresponding $t$-statistics (Note 9). In panel A, the average return is $0.485 \%$ with a standard deviation of $0.309 \%$. The monthly Sharpe ratios have a mean of 0.045 and a standard deviation of 0.055 , with a range from -0.306 to 0.232 . The Fama-French alpha estimates have a mean of $-0.064 \%(t$-stat. $=-1.16)$ and a standard deviation of $0.267 \%$. Approximately $60 \%$ of funds have negative performance values. At the 5\% level, approximately $10 \%(2 \%)$ of funds have significantly negative (positive) alpha estimates. In panel B, industry portfolios have mean returns from $0.356 \%$ to $0.999 \%$ and standard deviations from $3.816 \%$ to $8.233 \%$.

Table 1. Summary statistics

\begin{tabular}{|c|c|c|c|c|c|c|c|}
\hline \multicolumn{8}{|c|}{ Panel A. Mutual Fund Returns and Fama-French Alphas } \\
\hline & Mean & StdDev & Min & Max & $h$ & $\alpha_{M F, F F}$ & $t$-statistics \\
\hline Mean & 0.4848 & 5.6633 & -19.1187 & 16.1357 & 0.0452 & -0.0637 & -0.3924 \\
\hline StdDev & 0.3091 & 1.6530 & 4.9232 & 7.5524 & 0.0547 & 0.2607 & 1.2285 \\
\hline$(t$-stat $)$ & & & & & & $(-1.161)$ & \\
\hline $99 \%$ & 1.1755 & 10.5577 & -5.2848 & 40.5801 & 0.1537 & 0.5577 & 2.2049 \\
\hline $95 \%$ & 0.9323 & 8.5988 & -12.7480 & 32.1314 & 0.1220 & 0.2798 & 1.5057 \\
\hline $90 \%$ & 0.8391 & 7.6060 & -14.2134 & 26.8592 & 0.1061 & 0.1988 & 1.1115 \\
\hline $75 \%$ & 0.6623 & 6.3709 & -16.2791 & 18.3857 & 0.0791 & 0.0698 & 0.4345 \\
\hline Median & 0.4897 & 5.3792 & -18.6207 & 13.8677 & 0.0517 & -0.0517 & -0.3555 \\
\hline $25 \%$ & 0.3410 & 4.7017 & -21.7059 & 11.3099 & 0.0207 & -0.1723 & -1.1245 \\
\hline $10 \%$ & 0.1223 & 4.1858 & -24.6343 & 9.7340 & -0.0264 & -0.3199 & -1.9346 \\
\hline $5 \%$ & -0.0178 & 3.7186 & -26.4187 & 8.8372 & -0.0550 & -0.4475 & -2.5100 \\
\hline $1 \%$ & -0.3862 & 1.6135 & -35.9893 & 5.0661 & -0.1179 & -0.9014 & -3.8027 \\
\hline \multicolumn{8}{|c|}{ Panel B. Passive Portfolio Returns } \\
\hline & \multicolumn{2}{|c|}{ Mean } & StdDev & \multicolumn{2}{|l|}{ Min } & Max & $h$ \\
\hline NoDur & \multicolumn{2}{|c|}{0.6734} & 3.8159 & \multicolumn{2}{|l|}{-13.0900} & 10.9000 & 0.1226 \\
\hline Durbl & \multicolumn{2}{|c|}{0.5574} & 8.1845 & \multicolumn{2}{|l|}{-32.8900} & 42.9200 & 0.0431 \\
\hline Manuf & \multicolumn{2}{|c|}{0.7896} & 5.4291 & \multicolumn{2}{|l|}{-20.9400} & 17.7800 & 0.1077 \\
\hline Enrgy & \multicolumn{2}{|c|}{0.9989} & 6.1105 & \multicolumn{2}{|l|}{-17.1200} & 19.1300 & 0.1301 \\
\hline HiTec & \multicolumn{2}{|c|}{0.7310} & 8.2327 & \multicolumn{2}{|l|}{-26.1500} & 20.4600 & 0.0640 \\
\hline Telcm & \multicolumn{2}{|c|}{0.4103} & 5.9385 & \multicolumn{2}{|l|}{-15.5600} & 22.1200 & 0.0346 \\
\hline Shops & \multicolumn{2}{|c|}{0.7485} & 4.8399 & \multicolumn{2}{|l|}{-15.1600} & 13.3800 & 0.1122 \\
\hline Hlth & \multicolumn{2}{|c|}{0.6037} & 4.2342 & \multicolumn{2}{|l|}{-12.3600} & 12.0300 & 0.0944 \\
\hline Utils & \multicolumn{2}{|c|}{0.6949} & 4.4358 & \multicolumn{2}{|l|}{-12.6500} & 11.7600 & 0.1107 \\
\hline Other & \multicolumn{2}{|c|}{0.3556} & 5.7347 & \multicolumn{2}{|l|}{-21.2800} & 16.1100 & 0.0264 \\
\hline $\mathrm{RF}$ & \multicolumn{2}{|c|}{0.2047} & 0.1721 & 0.0000 & & 0.5600 & --- \\
\hline
\end{tabular}

Note. This table presents summary statistics for the monthly data from January 1998 to December 2012. Panel A shows cross-sectional summary statistics (mean, standard deviation (StdDev) and selected percentiles) on the distributions of the mean, standard deviation (StdDev), minimum (Min), maximum (Max), Sharpe ratio $(h)$ and Fama-French SDF alphas $\left(\alpha_{M F, F F}\right)$ with their corresponding $t$-statistics for the net-of-fee returns on 2530 actively-managed open-ended U.S. equity mutual funds. It also reports the $t$-statistics ( $t$-stat) on the significance of the mean of estimated Fama-French SDF alphas. Panel B gives the mean, standard deviation (StdDev), minimum (Min), maximum (Max) and Sharpe ratio $(h)$ for the passive portfolio returns. The passive portfolios include ten industry portfolios (consumer nondurables (NoDur), consumer durables (Dur), manufacturing (Manuf), energy (Enrgy), high technology (HiTec), telecommunication (Telcm), shops (Shops), healthcare (Hlth), utilities (Utils), and other industries (Other)), and the risk-free asset (RF) based on the one-month Treasury bills. Results are in percentage except for the Sharpe ratios and the $t$-statistics.

\section{Style Classification}

This section introduces a method to exploit available style classification data in the CRSP fund database better. It also argues that the resulting style classifications and style portfolios, defined by size and value sorts, are relevant choices toward identifying meaningful clienteles in mutual funds. For the purpose of this study, a good style classification method should meet two objectives. First, it should be based on publicly and easily available information that clienteles could presumably consult to form their investment decisions. This objective leads us to avoid using the statistical methods proposed by Sharpe (1992), Brown and Goetzmann (1997) and others, to 
instead rely on existing classifications from industry providers.

Second, the classification should be based on styles commonly accepted by mutual fund investors. As discussed earlier, industry practices and academic researchers have long recognized the importance of size (small-cap versus large-cap) and value (value versus growth) investors. As a result, over the last 20 years, many equity funds have advertised themselves according to their size and value focuses to cater to size and value investors, who can rely on classification tools like the style box popularized by Morningstar and illustrated in figure 1. To reach our style classification goals, the method detailed in the rest of this section thus uses existing industry classifications to split funds into size and value style categories.

\subsection{Style Classification Data from the CRSP Mutual Fund Database}

The CRSP Survivor-Bias Free Mutual Fund US Database provides style codes from three sources: Wiesenberger, Strategic Insight and Lipper (Note 10). Each source is only available for a part of the CRSP data period: from 1962 to 1993 for Wiesenberger, from 1993 to 1998 for Strategic Insight and since 1998 for Lipper. This paper focuses on the period with Lipper data for two main reasons. First, Lipper codes cover most of the period during which size and value investment styles are prevalent in the industry. The Lipper period is likely the most relevant period to identify size and value clienteles. Second, Lipper codes facilitate the classification of equity funds into size and value styles because they are named according to these styles. In particular, they include large-cap growth funds (code LCGE), small-cap growth funds (code SCGE), large-cap value funds (code LCVE) and small-cap value funds (code SCVE). Hence, focusing on the Lipper period avoids the ad hoc attribution of Wiesenberger and Strategic Insight codes into the style categories considered in this paper (Note 11). Lipper, a Thomson Reuters company, is also a global leader in supplying fund information and thus a source regularly consulted by fund clienteles (Note 12).

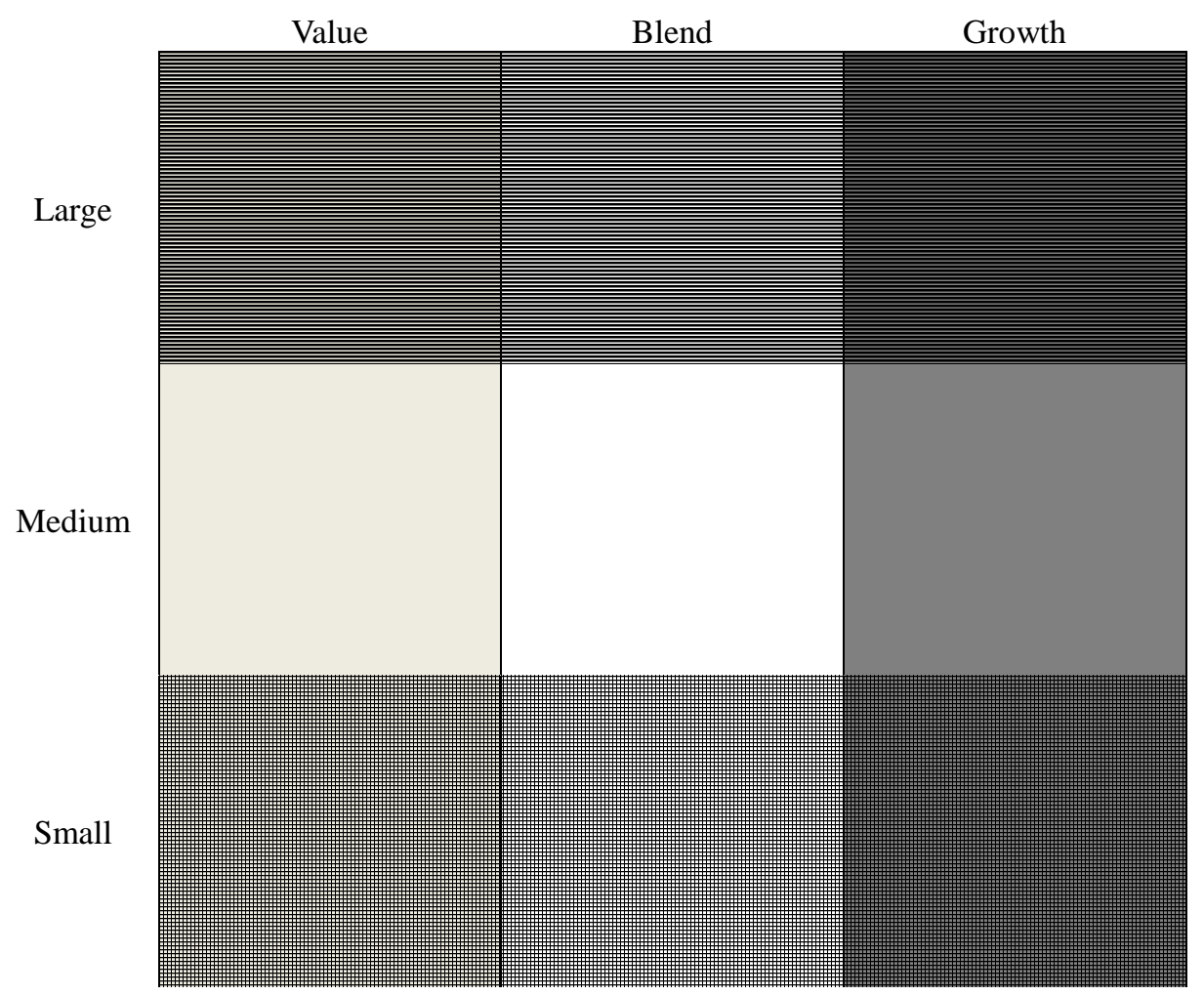

Figure 1. Mutual fund style box

Note. This figure presents a mutual fund style box to illustrate the classification of funds. Corner funds represent funds categorized according to a narrow style definition and are located in the four hatched-colored boxes. They include large-cap value funds (box in light gray with horizontal lines), large-cap growth funds (box in dark gray with horizontal lines), small-cap value funds (box in light gray with squared lines) and small-cap growth funds (box in dark gray with squared lines). SLVG funds represent funds categorized according to a broad style definition by combining corner funds with a common style. They include small-cap funds (corner boxes with squared lines), large-cap funds (corner boxes with horizontal lines), value funds (corner boxes in light gray) and growth funds (corner boxes in dark gray). Mixed funds represent funds that are not corner funds (boxes in the medium row and blend column). Other funds represent funds with a style that does not fit into the style box. 
An important issue arising from Lipper codes in the CRSP database is that, although a unique classification code is typically attributed to a fund for a given period (which can be a month up to its full sample period), it can frequently change through time or be missing. Panel A of table 2 reports statistics to assess the coverage and stability of the Lipper classification codes available for the 2530 equity mutual funds in our sample. It provides the mean, standard deviation (StdDev) and selected percentiles of the distributions of the numbers of code changes per fund ( $\mathrm{Nb}$ Changes), the numbers of different codes per fund ( $\mathrm{Nb}$ Styles), the maximum proportions of monthly observations that a fund has the same code (\% Max) and the proportions of monthly observations that a fund presents a missing code (\% Missing).

The results show that frequent changes in codes are a bigger issue than missing codes. On average, funds have 3.77 code changes and 3.19 different codes from 1998 to 2012. Less than $1 \%$ of the funds have no code change. But more than $10 \%$ of the funds have at least six code changes and four different codes. One fund even goes through 11 different codes. Although code changes are frequent, many funds keep the same code for a large fraction of their observations. On average, funds spend $67.46 \%$ of their sample observations with the same code and one fourth of the funds have the same code for at least $82 \%$ of their observations. The fraction of funds with less than half (a quarter) of their observations with the same code is approximately equal to $20 \%(0.5 \%)$. Finally, the proportions of months with missing codes average $12.83 \%$. Only $1 \%$ of the funds have no missing code, but less than $5 \%$ of the funds have more than $25.75 \%$ of missing codes. Our style classification method accounts for both code changes and missing codes.

Table 2. Style classification of mutual funds

\begin{tabular}{|c|c|c|c|c|}
\hline \multicolumn{5}{|c|}{ Panel A. Lipper Classification Codes } \\
\hline & $\mathrm{Nb}$ Changes & $\mathrm{Nb}$ Styles & $\% \operatorname{Max}$ & $\%$ Missing \\
\hline Mean & 3.77 & 3.19 & 67.46 & 12.83 \\
\hline StdDev & 2.01 & 1.00 & 17.12 & 6.09 \\
\hline $\operatorname{Max}$ & 13 & 11 & 100.00 & 47.40 \\
\hline $99 \%$ & 10 & 6 & 93.00 & 31.60 \\
\hline $95 \%$ & 8 & 5 & 89.83 & 25.75 \\
\hline $90 \%$ & 6 & 4 & 89.83 & 22.24 \\
\hline $75 \%$ & 5 & 4 & 82.30 & 14.64 \\
\hline Median & 3 & 3 & 69.45 & 10.18 \\
\hline $25 \%$ & 2 & 3 & 53.61 & 10.18 \\
\hline $10 \%$ & 2 & 2 & 43.84 & 7.72 \\
\hline $5 \%$ & 1 & 2 & 38.98 & 7.00 \\
\hline $1 \%$ & 1 & 2 & 30.51 & 0.00 \\
\hline Min & 0 & 1 & 19.08 & 0.00 \\
\hline \multicolumn{5}{|c|}{ Panel B. Style Classification of Mutual Funds } \\
\hline Style Classification & & & $50 \%$ & $75 \%$ \\
\hline LCG & & & 168 & 41 \\
\hline SCG & & & 135 & 42 \\
\hline LCV & & & 70 & 14 \\
\hline SCV & & & 53 & 8 \\
\hline Small & & & 188 & 50 \\
\hline Large & & & 238 & 55 \\
\hline Value & & & 123 & 22 \\
\hline Growth & & & 303 & 83 \\
\hline Mixed & & & 1899 & 2220 \\
\hline Other & & & 205 & 205 \\
\hline
\end{tabular}

Note. This table presents summary statistics for the style classification of mutual funds. Panel A is based on the Lipper classification codes in the CRSP Surviror-Bias-Free US Mutual Fund Database. It gives the mean, standard deviation (StdDev) and selected percentiles of the numbers of code changes per fund ( $\mathrm{Nb}$ Changes), the numbers of different codes per fund (Nb Styles), the maximum proportions of monthly observations that a fund has the same code (\% Max) and the proportions of monthly observations that a fund presents a missing code ( $\%$ Missing). Panel B reports the number of funds classified into each style using the style classification method described in section 4.2 and three values of the threshold for style inclusion: $25 \%, 50 \%$ and $75 \%$. The classification depends on whether the proportions of monthly return observations associated with the Lipper codes attached to the funds are above the given threshold for style inclusion. Funds are classified into ten styles: four corner styles (LCG, SCG, LCV and SCV), four SLVG styles (Small, Large, Value and Growth), the Mixed style and the Other style. The corner styles include large-cap growth (LCG) funds, small-cap growth (SCG) funds, large-cap value (LCV) funds and small-cap value (SCV) funds. The SLVG styles include small-cap (Small) funds, large-cap (Large) funds, value (Value) funds and growth (Growth) funds. The data cover the period January 1998-December 2012. 


\subsection{Style Classification Method and Results}

This section describes our style classification method and presents the classification results for the funds. Figure 1 presents a mutual fund style box that illustrates the classification. The method proceeds in five steps. First, we start by identifying all funds with at least one of the four Lipper codes that jointly consider the size and value styles (i.e., codes LCGE, SCGE, LCVE and SCVE). Second, to deal with code changes and missing codes, we compute the proportion of monthly return observations associated with each code attached to each identified fund. One minus the sum of these "Lipper code proportions" gives the fraction of observations with a missing code.

Third, if its corresponding Lipper code proportion is above a given threshold, we assign a fund to one of the following four specialized styles: large-cap growth (LCG), small-cap growth (SCG), large-cap value (LCV) and small-cap value (SCV). For example, if we select a threshold of 50\%, then a fund is classified as LCV only if its Lipper code is LCVE for $50 \%$ of its return observations. This "threshold for style inclusion" ensures that the Lipper code information is sufficiently reliable for the fund to be categorized, i.e. a fund with different or missing codes for a significant fraction of its sample period is not assigned to a style. As LCG, SCG, LCV and SCV funds are in the corners of the style box in figure 1, we call them "corner" funds for brevity.

Fourth, we form four broader style categories by combining corner funds with a common style. Hence, we assign the Small style to SCV and SCG funds, the Large style to LCV and LCG funds, the Value style to SCV and LCV funds and the Growth style to SCG and LCG funds. We refer to Small, Large, Value and Growth funds as "SLVG" funds for brevity. Fifth, we assign either the Mixed style or the Other style to funds not categorized as corner funds. The Mixed style includes funds that do not meet the threshold for style inclusion defined previously or are assigned to the Lipper codes associated with the Medium row or Blend column of the style box in figure 1 (Note 13). The Other style includes funds with a style that does not fit into the style box (Note 14).

The previous five steps result in a total of ten categories: four corner styles (LCG, SCG, LCV and SCV), four SLVG styles (Small, Large, Value and Growth), the Mixed style and the Other style. Panel B of table 2 reports the number of funds classified into each style for three thresholds for style inclusion: 25\%, 50\% and 75\% (Note 15). Intuitively, the threshold determines the "style purity" of the corner funds. When its value is $75 \%$, the numbers are small and vary from 8 SCV funds to 42 SCG funds. Most funds end up in the Mixed style because they do not have the required codes for $75 \%$ of their observations. When the threshold is $50 \%$, the numbers increase considerably and include $53 \mathrm{SCV}$ funds, $70 \mathrm{LCV}$ funds, 135 SCG funds and $168 \mathrm{LCG}$ funds. The SLVG funds are divided into 188 Small funds, 238 Large funds, 123 Value funds and 303 Growth funds. When the threshold is $25 \%$, the numbers are above 100 for all corner styles, above 290 for all SLVG styles and equal to 1532 for the Mixed style. Finally, there are 205 funds in the Other style for all values of the threshold.

\subsection{Style Portfolios and Upper Performance Bound Choice}

This section examines results for portfolios of funds classified into the ten previously identified style categories. The style portfolios constructed from the corner and SLVG funds are used to extract the style SDFs with the approach discussed in section 2.2. To make these portfolios as representative of their style as possible, we select a threshold for style inclusion of 50\% in the fund classification method. This threshold ensures that the funds included in the portfolios are assigned to the desired style for a majority of their monthly observations and are in sufficient numbers to provide adequate portfolio diversification (i.e., low fund-specific risk).

Table 3 presents summary statistics, including Fama-French SDF alphas and their $t$-statistics, for the monthly returns on two types of portfolios: net asset value-weighted (NAV-weighted) portfolios (panel A) and equally-weighted portfolios (panel B). The NAV-weighted portfolios in panel A have mean returns from $0.413 \%$ to $0.821 \%$ and standard deviations from $4.576 \%$ to $7.150 \%$. Their Sharpe ratios and Fama-French alphas vary from 0.044 to 0.110 and from $-0.084 \%$ to $0.193 \%$, respectively. The equally-weighted portfolios in panel B have mean returns from $0.418 \%$ to $0.734 \%$ and standard deviations from $4.315 \%$ to $7.018 \%$. Their Sharpe ratios and Fama-French alphas vary from 0.046 to 0.105 and from $-0.098 \%$ to $0.146 \%$, respectively. No Fama-French alpha is statistically significant at the $5 \%$ level. Overall, the portfolios of small-cap funds, value funds and other funds tend to earn more.

Two findings from table 3 impact the rest of our analysis. First, the results in panels A and B are relatively similar and suggest that the type of weights for the style portfolios is not a material choice. Based on this assessment, we focus on NAV-weighted portfolios, which better account for the invested amounts of investors, to identify the SDFs used in our style-clientele-specific performance evaluation. In unreported results, we confirm that the SDFs identified from equally-weighted portfolios are similar to those identified from NAV-weighted portfolios.

Second, as discussed in section 3.1, the Fama-French alphas are used to select a relevant value for the upper 
performance bound of the style portfolios, $\bar{\alpha}_{s}$, which is needed to estimate the disagreement parameter of the style SDFs. The alphas in table 3 , combined with the mean $(0.248 \%)$ and median $(0.212 \%)$ bound values reported by FL, allow us to make a selection. We find that the clienteles most favorable to the corner and SLVG (NAV-weighted) style portfolios should expect mean alphas from $0.164 \%$ to $0.299 \%$ and median alphas from $0.128 \%$ to $0.263 \%$. Based on these ranges, we opt for $\bar{\alpha}_{s}=0.15 \%$ as a realistic yet conservative value. In section 5.4, we examine the sensitivity of our results to this choice by considering values of $\bar{\alpha}_{s}=0 \%$ and $\bar{\alpha}_{s}=$ $0.3 \%$, which respectively assume that style clienteles expect either no performance or a high performance from their preferred style portfolios.

Table 3. Summary statistics for mutual fund style portfolios

\begin{tabular}{|c|c|c|c|c|c|c|c|}
\hline \multicolumn{8}{|c|}{ Panel A. Returns and Fama-French Alphas for NAV-Weighted Mutual Fund Style Portfolios } \\
\hline Style Classification & Mean & StdDev & Min & Max & $h$ & $\alpha_{S, F F}$ & $t$-statistics \\
\hline LCG & 0.4482 & 5.4292 & -16.8991 & 12.4339 & 0.0477 & -0.0720 & -0.9200 \\
\hline SCG & 0.7082 & 7.1505 & -22.0506 & 27.0381 & 0.0707 & -0.0830 & -0.7800 \\
\hline $\mathrm{LCV}$ & 0.4128 & 4.6562 & -16.9076 & 11.7733 & 0.0450 & -0.0720 & -0.9200 \\
\hline SCV & 0.8206 & 5.5741 & -21.3388 & 17.7120 & 0.1084 & 0.0514 & 0.4200 \\
\hline Small & 0.7691 & 6.5758 & -21.0640 & 23.3101 & 0.0851 & -0.0350 & -0.4000 \\
\hline Large & 0.4169 & 5.0808 & -16.8712 & 11.7631 & 0.0437 & -0.0840 & -1.4700 \\
\hline Value & 0.5760 & 4.9469 & -19.1288 & 14.1630 & 0.0745 & -0.0080 & -0.0900 \\
\hline Growth & 0.4933 & 5.6334 & -17.9827 & 13.6074 & 0.0534 & -0.0610 & -0.8200 \\
\hline Mixed & 0.5450 & 4.8643 & -18.0761 & 11.3832 & 0.0692 & -0.0030 & -0.0900 \\
\hline Other & 0.7079 & 4.5765 & -18.6406 & 10.6618 & 0.1103 & 0.1927 & 1.9200 \\
\hline \multicolumn{8}{|c|}{ Panel B. Returns and Fama-French Alphas for Equally-Weighted Mutual Fund Style Portfolios } \\
\hline Style Classification & Mean & StdDev & Min & Max & $h$ & $\alpha_{S, F F}$ & $t$-statistics \\
\hline LCG & 0.4412 & 5.3274 & -16.9975 & 12.2806 & 0.0457 & -0.0680 & -0.8100 \\
\hline SCG & 0.6979 & 7.0176 & -21.4409 & 24.1058 & 0.0690 & -0.0980 & -0.9800 \\
\hline LCV & 0.4179 & 4.5526 & -16.4539 & 11.6782 & 0.0461 & -0.0680 & -0.8100 \\
\hline SCV & 0.7344 & 5.3197 & -20.6288 & 16.1120 & 0.0975 & 0.0122 & 0.0900 \\
\hline Small & 0.7078 & 6.3206 & -20.9842 & 17.8977 & 0.0781 & -0.0680 & -0.7800 \\
\hline Large & 0.4292 & 4.9289 & -16.8034 & 11.6983 & 0.0464 & -0.0710 & -1.4500 \\
\hline Value & 0.5517 & 4.7368 & -18.1392 & 12.8513 & 0.0718 & -0.0340 & -0.3400 \\
\hline Growth & 0.5566 & 5.9526 & -18.9806 & 15.2024 & 0.0591 & -0.0810 & -1.1300 \\
\hline Mixed & 0.5165 & 4.9201 & -18.0184 & 11.9546 & 0.0627 & -0.0580 & -1.1300 \\
\hline Other & 0.6548 & 4.3148 & -18.9360 & 9.9330 & 0.1048 & 0.1463 & 1.4300 \\
\hline
\end{tabular}

Note. This table presents summary statistics for the monthly returns on net asset value-weighted (NAV-weighted) (panel A) and equally-weighted (panel B) style portfolios. The table shows the mean, standard deviation (StdDev), minimum (Min), maximum (Max), Sharpe ratio $(h)$ and Fama-French SDF alphas $\left(\alpha_{S, F F}\right)$ with their $t$-statistics of the portfolio returns. Using the style classification method described in section 4.2 and a $50 \%$ threshold for style inclusion, the funds are classified into ten styles: four corner styles (LCG, SCG, LCV and SCV), four SLVG styles (Small, Large, Value and Growth), the Mixed style and the Other style. The corner styles include large-cap growth (LCG) funds, small-cap growth (SCG) funds, large-cap value (LCV) funds and small-cap value (SCV) funds. The SLVG styles include small-cap (Small) funds, large-cap (Large) funds, value (Value) funds and growth (Growth) funds. One NAV-weighted portfolio and one equally-weighted portfolio are formed for each style. The data cover the period January 1998-December 2012. Results are in percentage except for the Sharpe ratios and the $t$-statistics.

\section{Empirical Results}

\subsection{Clientele-Specific Style Stochastic Discount Factors}

We begin by examining the empirical style SDFs identified from the NAV-weighted style portfolios and an upper performance bound of $\bar{\alpha}_{s}=0.15 \%$. Our classification method results in eight clientele-specific styles. The four SLVG styles (Small, Large, Value, Growth) are general and should attract broad clienteles who consider either the size or value focus of equity funds. Accordingly, we refer to the SDFs identified from the SLVG portfolios as the broad style SDFs. The four corner styles (LCG, SCG, LCV, SCV) are more specific and should attract specialized clienteles who jointly consider the size and value focuses of funds. Accordingly, we refer to the SDFs extracted from the corner portfolios as the narrow style SDFs. 
Table 4. Statistics for the clientele-specific style stochastic discount factors

\begin{tabular}{|c|c|c|c|c|c|c|c|c|c|}
\hline \multicolumn{10}{|c|}{ Panel A. Distributions of Style SDFs } \\
\hline & \multicolumn{5}{|c|}{ Broad Style SDFs } & \multicolumn{4}{|c|}{ Narrow Style SDFs } \\
\hline & Small & Large & Value & \multicolumn{2}{|c|}{ Growth } & LCG & SCG & LCV & SCV \\
\hline Mean & 0.9979 & 0.9980 & 0.9980 & \multicolumn{2}{|c|}{0.9980} & 0.9980 & 0.9979 & 0.9979 & 0.9979 \\
\hline StdDev & 0.2691 & 0.5307 & 0.3456 & \multicolumn{2}{|c|}{0.3926} & 0.4202 & 0.2768 & 0.4920 & 0.2654 \\
\hline Autocorr & 0.046 & 0.094 & -0.012 & \multicolumn{2}{|c|}{0.076} & $0.141^{*}$ & 0.041 & $-0.132^{*}$ & 0.038 \\
\hline $99 \%$ & 1.6797 & 2.2689 & 1.8602 & \multicolumn{2}{|c|}{2.1642} & 2.2094 & 1.6767 & 2.4272 & 1.6545 \\
\hline $95 \%$ & 1.4818 & 1.9003 & 1.5829 & \multicolumn{2}{|c|}{1.5972} & 1.6521 & 1.5001 & 1.7381 & 1.4777 \\
\hline $90 \%$ & 1.3841 & 1.6542 & 1.4490 & \multicolumn{2}{|c|}{1.4444} & 1.4883 & 1.3887 & 1.6597 & 1.3803 \\
\hline $75 \%$ & 1.1552 & 1.3703 & 1.2136 & \multicolumn{2}{|c|}{1.2453} & 1.2848 & 1.1484 & 1.2686 & 1.1564 \\
\hline Median & 0.9778 & 0.9760 & 1.0111 & \multicolumn{2}{|c|}{0.9949} & 0.9751 & 0.9744 & 0.9639 & 0.9713 \\
\hline $25 \%$ & 0.8151 & 0.6718 & 0.7747 & \multicolumn{2}{|c|}{0.7747} & 0.7569 & 0.8135 & 0.6924 & 0.8199 \\
\hline $10 \%$ & 0.6719 & 0.3740 & 0.5420 & \multicolumn{2}{|c|}{0.5290} & 0.5354 & 0.6497 & 0.4243 & 0.6822 \\
\hline $5 \%$ & 0.5968 & 0.0843 & 0.4130 & \multicolumn{2}{|c|}{0.3924} & 0.2996 & 0.5750 & 0.2566 & 0.6108 \\
\hline $1 \%$ & 0.4008 & -0.3958 & 0.2733 & \multicolumn{2}{|c|}{-0.0868} & -0.0936 & 0.3475 & -0.2323 & 0.3967 \\
\hline Panel B. C & elations b & ween Style SI & & & & & & & \\
\hline & Small & Large & Value & Growth & & LCG & SCG & LCV & SCV \\
\hline Small & 1.000 & $0.510^{* * *}$ & $0.793^{* * *}$ & $0.739^{* * * *}$ & & $0.638^{* * *}$ & $0.992^{* * *}$ & $0.465^{* * *}$ & $0.991^{* * *}$ \\
\hline Large & & 1.000 & $0.161^{* *}$ & $0.869^{* * *}$ & & $0.958^{* * *}$ & $0.536^{* * *}$ & 0.035 & $0.485^{* * *}$ \\
\hline Value & & & 1.000 & $0.395^{* * *}$ & & $0.232^{* * *}$ & $0.773^{* * *}$ & $0.652^{* * *}$ & $0.794^{* * *}$ \\
\hline Growth & & & & 1.000 & & $0.927^{* * * *}$ & $0.792^{* * *}$ & -0.021 & $0.680^{* * *}$ \\
\hline LCG & & & & & & 1.0000 & $0.660^{* * *}$ & 0.012 & $0.616^{* * *}$ \\
\hline SCG & & & & & & & 1.000 & $0.395^{* * *}$ & $0.967^{* * *}$ \\
\hline LCV & & & & & & & & 1.000 & $0.534^{* * *}$ \\
\hline SCV & & & & & & & & & 1.000 \\
\hline Panel C. C & elations b & ween styres & is and State Va & ariables & & & & & \\
\hline & & Small & Large & Value & Growth & LCG & SCG & LCV & SCV \\
\hline Market Ret & & $-0.297^{* * *}$ & -0.098 & $-0.248^{* * *}$ & $-0.150^{* *}$ & $-0.149^{* *}$ & $-0.280^{* * * *}$ & $-0.201^{* * *}$ & $-0.313^{* * * *}$ \\
\hline Consumpti & Growth & $-0.138^{*}$ & -0.114 & $-0.223^{* * * *}$ & -0.082 & -0.085 & $-0.126^{*}$ & $-0.182^{* *}$ & $-0.148^{* * *}$ \\
\hline Labor Inco & Growth & -0.043 & 0.017 & -0.069 & 0.025 & 0.029 & -0.036 & -0.106 & -0.049 \\
\hline$\Delta$ Macro U & ertainty & $0.153^{* *}$ & 0.053 & $0.169^{* *}$ & 0.084 & 0.088 & $0.141^{*}$ & 0.086 & $0.160^{* *}$ \\
\hline Investor $\mathrm{Se}$ & iment & 0.090 & -0.057 & $0.133^{*}$ & 0.031 & -0.044 & 0.101 & 0.069 & 0.079 \\
\hline$\Delta$ Investor & ntiment & 0.100 & 0.019 & $0.133^{*}$ & 0.097 & 0.037 & 0.113 & 0.023 & 0.080 \\
\hline
\end{tabular}

Note. This table shows statistics for the broad and narrow style SDFs. The SDFs are estimated from NAV-weighted portfolios of funds classified using a threshold for style inclusion of 50\%. The columns labeled Small, Large, Value and Growth refer to results for the broad style SDFs obtained from funds classified into, respectively, the Small, Large, Value and Growth styles. The columns labeled LCG, SCG, LCV and SCV refer to results for the narrow style SDFs obtained from funds classified into, respectively, the LCG, SCG, LCV and SCV styles. Panel A provides the mean, standard deviation (StdDev), first-order autocorrelation (Autocorr) and selected percentiles of the distributions of the SDFs. Panel B provides correlations between the SDFs. Panel C provides correlations between the SDFs and state variables. The portfolio data (see statistics in table 3) cover the period January 1998-December 2012. ${ }^{* * *},{ }^{* *}$ and ${ }^{*}$ denote significance at the $1 \%$, $5 \%$ or $10 \%$ level.

Table 4 reports various statistics for the SDFs. Panel A presents the mean, standard deviation (StdDev), first-order serial correlation (Autocorr) and selected percentiles. As expected with a risk-free asset in the passive portfolios, all SDFs have the same mean. A more volatile SDF can be the result of a higher risk aversion (Hansen \& Jagannathan, 1991), but also of preferences that account for psychological biases and sentiment. The lowest SDF standard deviations are for the Small and SCV clienteles, and the highest values are for the Large and LCV clienteles. The SDF standard deviations for the Value versus Growth clienteles are closer. The SDF autocorrelations is related to economic time variation across two periods and should be close to zero according to observed returns (Chrétien, 2012). This is generally the case in table 4.

Panel B looks at the correlations between the SDFs. The results suggest that the broad and narrow clienteles are generally different. For the broad style SDFs, correlations are low between the Large and Value clienteles (Corr. = 0.16 ), the Value and Growth clienteles (Corr. $=0.40)$ and the Small and Large clienteles (Corr. $=0.51)$. The Large and Growth clienteles are the most related $($ Corr. $=0.87$ ). For the narrow style SDFs, correlations are low between 
the LCG and LCV clienteles (Corr. $=0.01$ ), the SCG and LCV clienteles (Corr. $=0.40)$ and the LCV and SCV clienteles $($ Corr. $=0.53)$. The only case where the style portfolios appear to fail to identify economically different style SDFs concerns the SCG and SCV SDFs (Corr. = 0.98). Furthermore, these SDFs are almost perfectly correlated with the Small SDFs, suggesting that it is difficult to distinguish between favorable preferences for value versus growth among small-cap investors.

Panel $\mathrm{C}$ and figure 2 study the relations between the SDFs and state variables, and find evidence for the rational and behavioral perspectives on the differences between style investors. We consider six state variables: two variables central to the main asset pricing models (market portfolio return and consumption growth), two variables relevant for the arguments that size and value investors have different aversion to recession / macroeconomic risk (labor income growth and change in macroeconomic uncertainty), and two variables from the behavioral finance literature (investor sentiment and change in investor sentiment) (Note 16). Panel C shows the correlations between the SDFs and these variables. Figure 2 illustrates the fitted results of modeling the broad style SDFs as cubic polynomial functions of the state variables, in the spirit of the literature on approximating the SDF with decompositions (Note 17).

From a rational perspective, the SDF should be monotone decreasing with the state of the economy (an implication of decreasing absolute risk aversion), so that the SDF is high in "bad" states and low in "good" states, with a more negative relation suggesting a more risk-averse clientele. The SDF should also be unrelated to state variables that do not capture risk. Panel $\mathrm{C}$ and figures $2 \mathrm{a}$ to $2 \mathrm{~d}$ find evidence consistent with the literature that the Value and Small SDFs show more aversion to market risk, consumption risk, labor income risk (to a lesser extent) and macroeconomic risk than the Growth and Large SDFs (Note 18). However, figure 2 suggests that extreme states drive the differences since the slopes are similar in "normal" states. For example, when market returns are between $-10 \%$ and $6 \%$, figure 2a shows that the SDFs are alike, which is consistent with the finding from Cronqvist et al. (2015) that growth and value investors have similar shares invested in risky securities. In extreme states, the figures indicate that the Large and Growth SDFs can become increasing in the state of the economy, a result known as a "pricing kernel puzzle" and documented by Rosenberg and Engle (2002) and others. The Value SDF is also positively related with investor sentiment and change in sentiment.

A behavioral perspective based on biased beliefs is helpful in explaining these differences in extreme states. Specifically, in our framework, the estimated SDFs should not only reflect the true style SDFs, but also an adjustment for the clientele's biased beliefs. This occurs because style investors presumably use their own subjective probabilities to form their expectations in evaluating funds according to equation (1), but the econometrician does not observe these probabilities and uses the available time series for estimation, which under stationarity and ergodicity, is linked to the physical (true) probabilities. To illustrate, let $P_{S}(\omega)$ be the subjective probability of clientele $s$ in state $\omega$ and let $P(\omega)$ be the corresponding physical probability. Then, we can establish the following relations:

$$
\begin{gathered}
\bar{\alpha}_{s}=E^{P_{S}}\left[m_{s} R_{S}\right]-1=\sum_{\omega}\left[P_{S}(\omega) \times m_{s}(\omega) \times R_{S}(\omega)\right]-1 \\
=\sum_{\omega}\left[P(\omega) \times\left(\frac{P_{S}(\omega)}{P(\omega)}\right) \times m_{S}(\omega) \times R_{S}(\omega)\right]-1=E^{P}\left[\left(\left(\frac{P_{S}(\omega)}{P(\omega)}\right) \times m_{S}\right) R_{S}\right]-1 .
\end{gathered}
$$

Thus, when taking expectations under the physical probabilities, we can use the true style SDF $m_{s}$ modified by an adjustment for biased beliefs $P_{S}(\omega) / P(\omega)$ to obtain the correct alpha. Using the available time series, the econometrician thus implicitly uncovers this adjusted SDF:

$$
\frac{1}{T} \sum_{t=1}^{T}\left[\left(\left(\frac{P_{s}\left(\omega_{t}\right)}{1 / T}\right) \times m_{s t}\right) R_{s t}\right]-1=\frac{1}{T} \sum_{t=1}^{T}\left[\bar{m}_{s t} R_{s t}\right]-1=\bar{\alpha}_{s} .
$$

The last equation shows that, from a behavioral perspective, an estimated style SDF $\bar{m}_{s t}$ could not only be influenced by state variables unrelated to risk within the true realized SDF $m_{s t}$, but it could also be increasing with the realized adjustment for biased beliefs $P_{s}\left(\omega_{t}\right) /(1 / T)$, so that it is higher (lower) when the clientele views a state as too probable (improbable) (Note 19). 
(a)

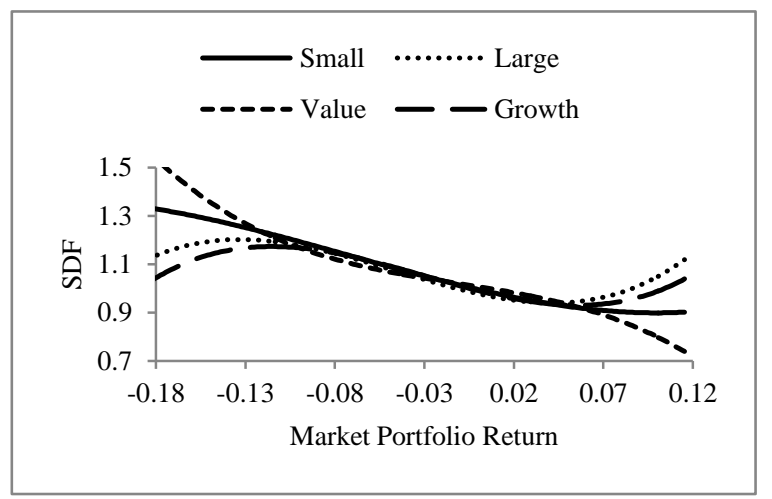

(c)

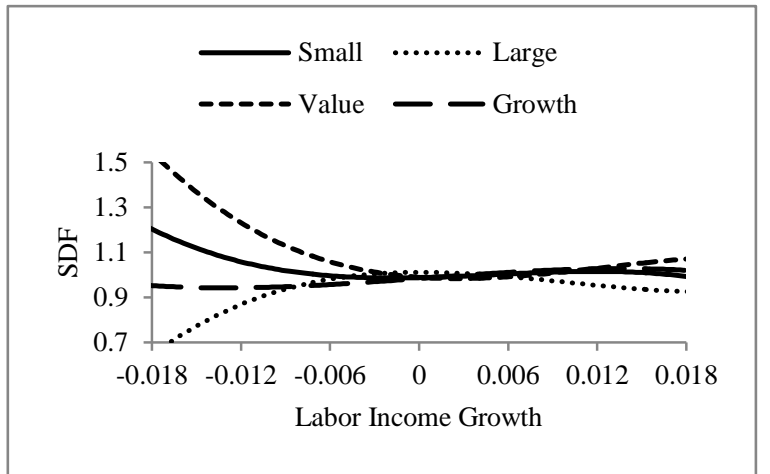

(e)

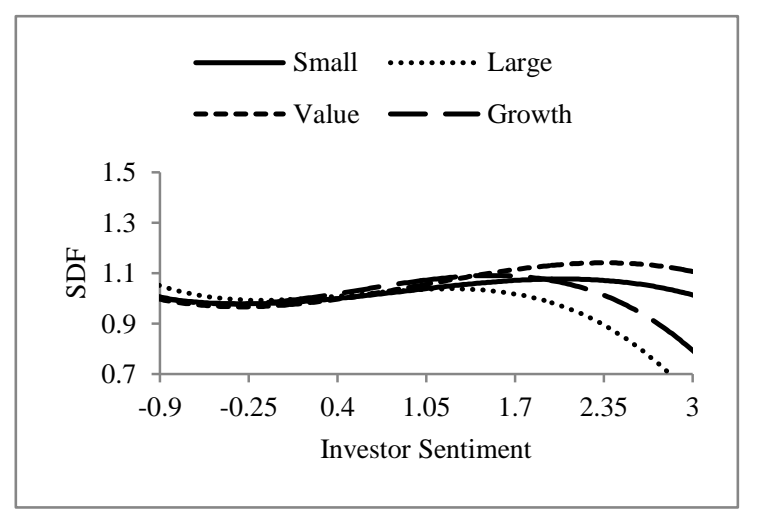

(b)

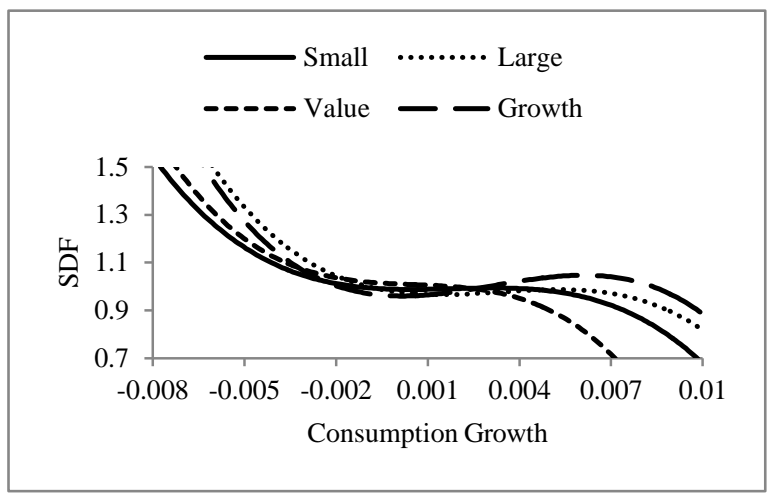

(d)

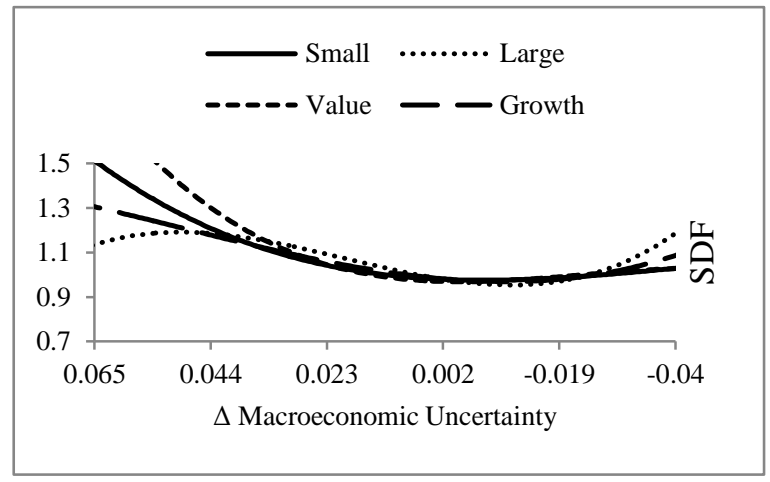

(f)

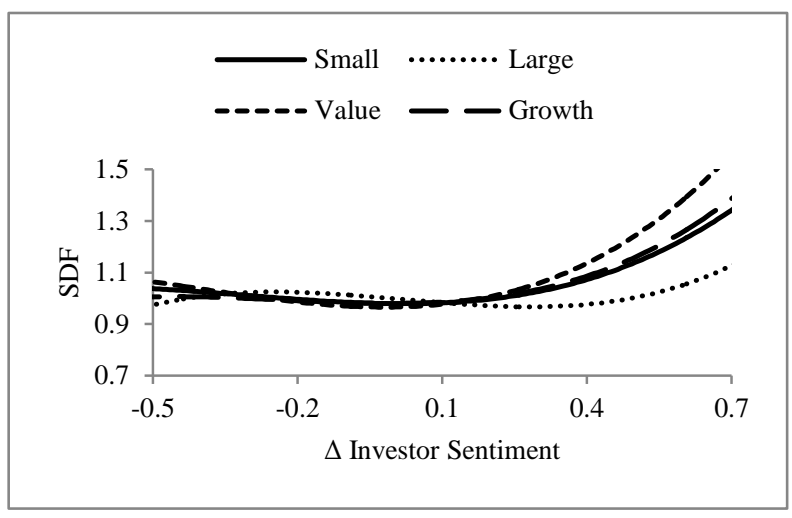

Figure 2. Broad style stochastic discount factors as cubic functions of state variables

Note. This figure illustrates the results of modeling the broad style SDFs as cubic functions of state variables, namely market portfolio return (figure 2a), consumption growth (figure 2b), labor income growth (figure 2c), change in macroeconomic uncertainty (figure 2d), investor sentiment (figure 2e) and change in investor sentiment (figure 2f).

When we focus on the SDF differences in extreme states, figure 2 shows evidence consistent with the literature that value and small-cap investors tend to be pessimists and contrarians, while growth and large-cap investors tend to be optimists and trend followers. In figures $2 \mathrm{a}$ to $2 \mathrm{~d}$, the Value and Small SDFs are generally higher (lower) than the Growth and Large SDFs in "bad" ("good") states. This suggests that the Value and Small clienteles view "tough" times as too probable and "easy" times as too improbable compared to the Growth and Large clienteles. In figures $2 \mathrm{e}$ and $2 \mathrm{f}$, the Value and (to a lesser extent) Small SDFs are higher than the Growth and Large SDFs when sentiment is high or increasing. Thus, the Value and Small (Growth and Large) clienteles view as too probable (improbable) the possibility that stocks are overvalued because of sentiment, and are thus contrarians (trend followers). 
In summary, this section shows that the estimated clientele-specific style SDFs are not only different, but they also have rational and behavioral features that are generally consistent with existing studies on size and value investors. The identified style clienteles should thus generate meaningful disagreement in performance evaluation.

\subsection{Style-Clientele-Specific Performance Evaluation Results}

This section examines clientele-specific performance evaluation using the style SDFs. As discussed in section 2.3, the evaluation necessitates that we distinguish between individual funds with and without clientele-specific styles. In our classification, the funds assigned to clientele-specific styles include SLVG funds and corner funds. Their performance measurement simply uses their associated style SDFs, i.e., the broad style SDFs for SLVG funds and the narrow style SDFs for corner funds. The funds classified in the Mixed and Other categories represent funds not assigned to clientele-specific styles. As they are not assigned to any unique style SDF, their performance measurement is done for all clienteles. To obtain a sufficiently large cross-section of funds in each style category, we select a threshold for style inclusion of $25 \%$ in the fund classification method. Intuitively, we thus stipulate that a fund assigned to a given style for at least $25 \%$ of its return observations should be of interest to its associated style clientele. Given this threshold, the number of funds in each cross-section is given in the row under 25\% in panel B of table 2 and varies from 102 SCV funds to 1532 Mixed funds.

Tables 5 to 10 present the style-clientele-specific performance evaluation results. Panel A of each table provides the mean, standard deviation (StdDev) and selected percentiles of the distributions of the estimated SDF alphas (columns under Performance) and their corresponding $t$-statistics (columns under $t$-statistics). It also reports the $t$-statistics ( $t$-stat) on the significance of the cross-sectional mean of estimated alphas using the test described in section 3.1, which accounts for the dependence in performance between funds. Panel B of each table gives the proportions of estimated alphas that are positive $\left(\% \alpha_{M F, S}>0\right)$ and negative $\left(\% \alpha_{M F, S}<0\right)$.

Table 5. Broad style-clientele-specific alphas for SLVG mutual funds

\begin{tabular}{|c|c|c|c|c|c|c|c|c|}
\hline \multicolumn{9}{|c|}{ Panel A. Performance and $t$-statistics } \\
\hline & \multicolumn{4}{|c|}{ Performance } & \multicolumn{4}{|c|}{$t$-statistics } \\
\hline & Small & Large & Value & Growth & Small & Large & Value & Growth \\
\hline Mean & 0.0003 & 0.0044 & 0.0579 & 0.2123 & -0.0176 & 0.1250 & 0.0777 & 0.2019 \\
\hline StdDev & 0.2811 & 0.3715 & 0.2672 & 0.4083 & 0.7277 & 0.3821 & 0.4098 & 0.4405 \\
\hline$(t$-stat $)$ & $(0.005)$ & $(0.056)$ & $(0.997)$ & $(2.426)$ & & & & \\
\hline $99 \%$ & 0.5759 & 1.0822 & 0.6942 & 1.1197 & 2.1082 & 1.3675 & 2.5134 & 1.7246 \\
\hline $95 \%$ & 0.4225 & 0.6395 & 0.5217 & 0.9628 & 1.0840 & 0.7924 & 0.6433 & 0.9862 \\
\hline $90 \%$ & 0.3448 & 0.4726 & 0.4330 & 0.7848 & 0.7587 & 0.5473 & 0.3866 & 0.6250 \\
\hline $75 \%$ & 0.1711 & 0.2392 & 0.2661 & 0.4934 & 0.2470 & 0.3511 & 0.2202 & 0.4109 \\
\hline Median & 0.0098 & -0.0219 & -0.0164 & 0.1424 & 0.0122 & -0.0221 & -0.0106 & 0.2102 \\
\hline $25 \%$ & -0.1330 & -0.2489 & -0.1382 & -0.0756 & -0.2690 & -0.1245 & -0.1145 & -0.0950 \\
\hline $10 \%$ & -0.3498 & -0.4587 & -0.2158 & -0.2661 & -0.7908 & -0.1951 & -0.2198 & -0.2545 \\
\hline $5 \%$ & -0.4884 & -0.5495 & -0.2962 & -0.3806 & -1.1516 & -0.2464 & -0.3326 & -0.3920 \\
\hline $1 \%$ & -0.8076 & -0.7302 & -0.4452 & -0.5979 & -2.3802 & -0.5447 & -0.7393 & -0.7063 \\
\hline \multicolumn{9}{|c|}{ Panel B. Performance Proportions } \\
\hline & & \multirow{2}{*}{\multicolumn{2}{|c|}{$\% \alpha_{M F, S}>0$}} & Small & Large & \multicolumn{2}{|c|}{ Value } & Growth \\
\hline \multicolumn{2}{|c|}{ Performance } & & & 51.63 & 47.84 & \multicolumn{2}{|c|}{47.42} & 65.34 \\
\hline \multicolumn{2}{|c|}{ Sign } & \multicolumn{2}{|c|}{$\% \alpha_{M F, S}<0$} & 48.37 & 52.16 & \multicolumn{2}{|c|}{52.58} & 34.66 \\
\hline
\end{tabular}

Note. This table shows statistics on the distribution of monthly SDF alphas for SLVG funds using the broad style SDFs. The columns labeled Small, Large, Value and Growth refer to results using, respectively, the Small, Large, Value and Growth SDFs for evaluation. The SLVG funds include funds classified into, respectively, the Small, Large, Value and Growth styles using a threshold for style inclusion of $25 \%$. Each fund is only evaluated with the SDF associated with its style. Panel A provides the mean, standard deviation (StdDev) and selected percentiles of the distributions of alphas (columns under Performance) and their $t$-statistics (columns under $t$-statistics). It also reports the $t$-statistics ( $t$-stat) on the significance of the mean of alphas. Panel B gives the proportions of estimated alphas that are positive $\left(\% \alpha_{M F, S}>0\right)$ and negative $\left(\% \alpha_{M F, S}<0\right)$. Results are in percentage except the $t$-statistics. 
Table 6. Narrow style-clientele-specific alphas for corner mutual funds

\begin{tabular}{|c|c|c|c|c|c|c|c|c|}
\hline \multicolumn{9}{|c|}{ Panel A. Performance and $t$-statistics } \\
\hline & \multicolumn{4}{|c|}{ Performance } & \multicolumn{4}{|c|}{$t$-statistics } \\
\hline & LCG & SCG & LCV & SCV & LCG & SCG & LCV & SCV \\
\hline Mean & 0.0758 & 0.0663 & 0.1005 & 0.0378 & 0.1922 & 0.2607 & 0.2620 & 0.0769 \\
\hline StdDev & 0.2670 & 0.3101 & 0.2022 & 0.1758 & 0.5610 & 0.8876 & 0.4938 & 0.6741 \\
\hline$(t$-stat $)$ & $(1.3069)$ & $(0.9690)$ & $(2.2447)$ & $(0.9320)$ & & & & \\
\hline $99 \%$ & 0.7725 & 0.6959 & 0.6600 & 0.4333 & 2.0107 & 2.5024 & 2.0237 & 1.5501 \\
\hline $95 \%$ & 0.5591 & 0.6017 & 0.4800 & 0.3120 & 1.1447 & 1.8948 & 1.4005 & 1.0487 \\
\hline $90 \%$ & 0.4089 & 0.4993 & 0.4156 & 0.2454 & 0.9112 & 1.3809 & 0.9091 & 0.8385 \\
\hline $75 \%$ & 0.2470 & 0.2244 & 0.1921 & 0.1542 & 0.5160 & 0.7101 & 0.3869 & 0.4169 \\
\hline Median & 0.0420 & 0.0568 & 0.0799 & 0.0475 & 0.1268 & 0.1780 & 0.1916 & 0.1180 \\
\hline $25 \%$ & -0.0846 & -0.0803 & -0.0171 & -0.0710 & -0.1329 & -0.1904 & -0.0203 & -0.2188 \\
\hline $10 \%$ & -0.2238 & -0.3165 & -0.1024 & -0.1746 & -0.4146 & -0.7009 & -0.2179 & -0.5486 \\
\hline $5 \%$ & -0.3202 & -0.4830 & -0.2352 & -0.2416 & -0.6515 & -1.2410 & -0.3694 & -1.1680 \\
\hline $1 \%$ & -0.5817 & -0.6943 & -0.3917 & -0.3246 & -1.3848 & -1.8933 & -0.7715 & -2.1845 \\
\hline \multicolumn{9}{|c|}{ Panel B. Performance Proportions } \\
\hline & & & & LCG & SCG & \multicolumn{2}{|c|}{$\mathrm{LCV}$} & SCV \\
\hline \multicolumn{2}{|c|}{ Performance } & \multicolumn{2}{|c|}{$\% \alpha_{M F, S}>0$} & 59.40 & 62.75 & \multicolumn{2}{|c|}{72.49} & 57.84 \\
\hline \multicolumn{2}{|c|}{ Sign } & \multicolumn{2}{|c|}{$\% \alpha_{M F, S}<0$} & 40.60 & 37.25 & \multicolumn{2}{|c|}{27.51} & 42.16 \\
\hline
\end{tabular}

Note. This table shows statistics on the distribution of monthly SDF alphas for corner funds using the narrow style SDFs. The columns labeled LCG, SCG, LCV and SCV refer to results using, respectively, the LCG, SCG, LCV and SCV SDFs for evaluation. The corner funds include funds classified into, respectively, the LCG, SCG, LCV and SCV styles using a threshold for style inclusion of $25 \%$. Each fund is only evaluated with the SDF associated with its style. Panel A provides the mean, standard deviation (StdDev) and selected percentiles of the distributions of alphas (columns under Performance) and their $t$-statistics (columns under $t$-statistics). It also reports the $t$-statistics $(t$-stat) on the significance of the mean of alphas. Panel B gives the proportions of alphas that are positive $\left(\% \alpha_{M F, S}>0\right)$ and negative $\left(\% \alpha_{M F, S}<0\right)$. Results are in percentage except the $t$-statistics.

Table 7. Broad style-clientele-specific alphas for mixed mutual funds

\begin{tabular}{|c|c|c|c|c|c|c|c|c|}
\hline \multicolumn{9}{|c|}{ Panel A. Performance and $t$-statistics } \\
\hline & \multicolumn{4}{|c|}{ Performance } & \multicolumn{4}{|c|}{$t$-statistics } \\
\hline & Small & Large & Value & Growth & Small & Large & Value & Growth \\
\hline Mean & -0.1455 & 0.0144 & -0.1491 & 0.0198 & -0.0818 & 0.0766 & -0.0131 & 0.0886 \\
\hline StdDev & 0.2840 & 0.3919 & 0.3458 & 0.3890 & 0.3152 & 0.3680 & 0.3329 & 0.3637 \\
\hline$(t$-stat $)$ & $(-2.361)$ & $(0.171)$ & $(-1.983)$ & $(0.238)$ & & & & \\
\hline $99 \%$ & 0.4476 & 1.1315 & 0.5094 & 1.0185 & 0.8308 & 1.4655 & 1.2540 & 1.3732 \\
\hline $95 \%$ & 0.2469 & 0.6598 & 0.3585 & 0.7263 & 0.3135 & 0.7279 & 0.5717 & 0.7468 \\
\hline $90 \%$ & 0.1615 & 0.4988 & 0.2409 & 0.5217 & 0.1855 & 0.4647 & 0.2899 & 0.5274 \\
\hline $75 \%$ & 0.0240 & 0.1753 & 0.0645 & 0.2388 & 0.0164 & 0.1907 & 0.0577 & 0.2517 \\
\hline Median & -0.1332 & -0.0269 & -0.1398 & -0.0402 & -0.0808 & -0.0190 & -0.0743 & -0.0253 \\
\hline $25 \%$ & -0.2772 & -0.1985 & -0.3239 & -0.2136 & -0.1750 & -0.1051 & -0.1498 & -0.1134 \\
\hline $10 \%$ & -0.4565 & -0.3669 & -0.5376 & -0.3703 & -0.3027 & -0.1916 & -0.2283 & -0.2089 \\
\hline $5 \%$ & -0.5982 & -0.4962 & -0.6973 & -0.5276 & -0.4232 & -0.2854 & -0.3128 & -0.3102 \\
\hline $1 \%$ & -1.0747 & -0.9099 & -1.2100 & -0.9042 & -1.2660 & -0.5887 & -0.8010 & -0.5373 \\
\hline \multicolumn{9}{|c|}{ Panel B. Performance Proportions } \\
\hline & & & & Small & Large & \multicolumn{2}{|c|}{ Value } & Growth \\
\hline \multicolumn{2}{|c|}{ Performance } & \multicolumn{2}{|c|}{$\% \alpha_{M F, S}>0$} & 28.20 & 45.89 & \multicolumn{2}{|c|}{32.11} & 45.56 \\
\hline \multicolumn{2}{|c|}{ Sign } & \multicolumn{2}{|c|}{$\% \alpha_{M F, S}<0$} & 71.80 & 54.11 & \multicolumn{2}{|c|}{67.89} & 54.44 \\
\hline
\end{tabular}

Note. This table shows statistics on the distribution of monthly SDF alphas for mixed funds using the broad style SDFs. The columns labeled Small, Large, Value and Growth refer to results using, respectively, the Small, Large, Value and Growth SDFs for evaluation. The Mixed funds include funds classified into the Mixed style using a threshold for style inclusion of 25\%. Each fund is evaluated with all SDFs. Panel A provides the mean, standard deviation (StdDev) and selected percentiles of the distributions of alphas (columns under Performance) and their $t$-statistics (columns under $t$-statistics). It also reports the $t$-statistics ( $t$-stat) on the significance of the mean of alphas. Panel B gives the proportions of alphas that are positive $\left(\% \alpha_{M F, S}>0\right)$ and negative $\left(\% \alpha_{M F, S}<0\right)$. Results are in percentage except the $t$-statistics. 
Table 8. Narrow style-clientele-specific alphas for mixed mutual funds

\begin{tabular}{|c|c|c|c|c|c|c|c|c|}
\hline \multicolumn{9}{|c|}{ Panel A. Performance and $t$-statistics } \\
\hline & \multicolumn{4}{|c|}{ Performance } & \multicolumn{4}{|c|}{$t$-statistics } \\
\hline & LCG & SCG & LCV & SCV & LCG & SCG & LCV & SCV \\
\hline Mean & -0.0564 & -0.1166 & -0.3124 & -0.1817 & 0.0279 & -0.0355 & -0.0086 & -0.1192 \\
\hline StdDev & 0.3373 & 0.2932 & 0.4674 & 0.2868 & 0.3543 & 0.3325 & 0.3928 & 0.2982 \\
\hline$(t$-stat $)$ & $(-0.770)$ & $(-1.802)$ & $(-3.018)$ & $(-2.742)$ & & & & \\
\hline $99 \%$ & 0.8247 & 0.5050 & 0.4891 & 0.3953 & 1.5483 & 1.1581 & 1.7774 & 0.7638 \\
\hline $95 \%$ & 0.4963 & 0.3093 & 0.3009 & 0.1975 & 0.6598 & 0.4256 & 0.5616 & 0.2373 \\
\hline $90 \%$ & 0.3576 & 0.2139 & 0.1795 & 0.1131 & 0.3732 & 0.2604 & 0.2366 & 0.1105 \\
\hline $75 \%$ & 0.0914 & 0.0583 & 0.0065 & -0.0145 & 0.0824 & 0.0445 & 0.0041 & -0.0091 \\
\hline Median & -0.0769 & -0.1193 & -0.2598 & -0.1540 & -0.0479 & -0.0696 & -0.0992 & -0.0945 \\
\hline $25 \%$ & -0.2275 & -0.2532 & -0.5396 & -0.3029 & -0.1187 & -0.1537 & -0.1535 & -0.1933 \\
\hline $10 \%$ & -0.3804 & -0.4464 & -0.8296 & -0.4827 & -0.2203 & -0.2560 & -0.2106 & -0.3651 \\
\hline $5 \%$ & -0.5547 & -0.5813 & -1.1026 & -0.6471 & -0.3309 & -0.3566 & -0.2667 & -0.5458 \\
\hline $1 \%$ & -0.9304 & -1.0235 & -1.8729 & -1.0740 & -0.7104 & -1.1077 & -0.5137 & -1.2016 \\
\hline \multicolumn{9}{|c|}{ Panel B. Performance Proportions } \\
\hline & & & & LCG & SCG & \multicolumn{2}{|c|}{ LCV } & SCV \\
\hline \multicolumn{2}{|c|}{ Performance } & \multicolumn{2}{|c|}{$\% \alpha_{M F, S}>0$} & 36.75 & 31.72 & \multicolumn{2}{|c|}{25.52} & 23.24 \\
\hline \multicolumn{2}{|c|}{ Sign } & \multicolumn{2}{|c|}{$\% \alpha_{M F, S}<0$} & 63.25 & 68.28 & \multicolumn{2}{|c|}{74.48} & 76.76 \\
\hline
\end{tabular}

Note. This table shows statistics on the distribution of monthly SDF alphas for mixed funds using the narrow style SDFs. The columns labeled LCG, SCG, LCV and SCV refer to results using, respectively, the LCG, SCG, LCV and SCV SDFs for evaluation. The Mixed funds include funds classified into the Mixed style using a threshold for style inclusion of 25\%. Each fund is evaluated with all SDFs. Panel A provides the mean, standard deviation (StdDev) and selected percentiles of the distributions of alphas (columns under Performance) and their $t$-statistics (columns under $t$-statistics). It also reports the $t$-statistics ( $t$-stat) on the significance of the mean of alphas. Panel B gives the proportions of alphas that are positive $\left(\% \alpha_{M F, S}>0\right)$ and negative $\left(\% \alpha_{M F, S}<0\right)$. Results are in percentage except the $t$-statistics.

Table 5 examines the results for the broader clienteles who consider either the size or value focus of equity funds. On average, small-cap, large-cap and value funds provide a relatively neutral performance to their respective clienteles, while growth funds provide a significantly positive performance to growth clienteles. Mean alphas are equal to $0.000 \%(t$-stat. $=0.00)$ for small-cap funds, $0.004 \%(t$-stat. $=0.06)$ for large-cap funds, $0.058 \%(t$-stat. $=$ $1.00)$ for value funds and $0.212 \%(t$-stat. $=2.43)$ for growth funds. The percentile statistics confirm that the alpha distributions are centered at approximately zero for small-cap, large-cap and value funds, although the $t$-statistic distributions show more significantly positive than negative alphas for large-cap and value funds. For growth funds, the alpha distribution is centered at a positive value and the proportions in panel B show that the fraction of positive alphas (65.34\%) is almost twice the fraction of negative alphas (34.66\%).

Table 6 provide the results for the narrower clienteles who jointly consider the size and value focuses of funds. The alphas have means of $0.076 \%(t$-stat. $=1.31)$ for large-cap growth funds, $0.066 \%(t$-stat. $=0.97)$ for small-cap growth funds, $0.101 \%(t$-stat. $=2.24)$ for large-cap value funds and $0.038 \%(t$-stat. $=0.93)$ for small-cap value funds. Although mean alphas are not significant for the funds assigned to three of the four styles, the percentiles of the distributions in panel A and the proportions in panel B indicate more positive than negative alphas for all four styles. Overall, tables 5 and 6 suggest that funds assigned to clientele-specific styles do not underperform for their clienteles. The performance of mutual funds could be more positive than existing evidence shows if the evaluation considers the relevant clienteles.

Tables 7 and 8 give the results for the 1532 Mixed mutual funds using respectively the broad and narrow style SDFs. These funds tend to fall in the Medium or Blend category of the style box and so could presumably be partly attractive for the style clienteles. In table 7, mean alphas vary from $-0.149 \%$ ( $t$-stat. $=-1.98$ ) to $0.020 \%$ $(t$-stat. $=0.24)$ and proportions of positive alphas vary from $28.20 \%$ to $45.89 \%$. In table 8 , mean alphas vary from $-0.312 \%(t$-stat. $=-3.02)$ to $-0.056 \%(t$-stat. $=-0.77)$ and proportions of positive alphas vary from $23.24 \%$ to $36.75 \%$. The performance of Mixed funds thus tends to be negative.

Tables 9 and 10 give the results for the 205 Other mutual funds using respectively the broad and narrow style SDFs. These funds are difficult to categorize because they do not fit into the style box. In table 9, mean alphas vary from $0.022 \%(t$-stat. $=0.37)$ to $0.200 \%(t$-stat. $=3.09)$ and proportions of positive alphas vary from $45.85 \%$ to $76.59 \%$. In table 10 , mean alphas vary from $-0.067 \%(t$-stat. $=-0.90)$ to $0.119 \%(t$-stat. $=2.00)$ and 
proportions of positive alphas vary from $44.39 \%$ to $63.90 \%$. The performance of Other funds is thus generally more positive.

Table 9. Broad style-clientele-specific alphas for other mutual funds

\begin{tabular}{|c|c|c|c|c|c|c|c|c|}
\hline \multicolumn{9}{|c|}{ Panel A. Performance and $t$-statistics } \\
\hline & \multicolumn{4}{|c|}{ Performance } & \multicolumn{4}{|c|}{$t$-statistics } \\
\hline & Small & Large & Value & Growth & Small & Large & Value & Growth \\
\hline Mean & 0.0220 & 0.1995 & 0.0398 & 0.1688 & 0.0388 & 0.2809 & 0.0607 & 0.2294 \\
\hline StdDev & 0.2749 & 0.3008 & 0.3396 & 0.3119 & 0.2552 & 0.4077 & 0.2395 & 0.3886 \\
\hline$(t$-stat $)$ & $(0.369)$ & $(3.093)$ & $(0.539)$ & $(2.526)$ & & & & \\
\hline $99 \%$ & 0.7604 & 0.9820 & 0.9750 & 1.0288 & 1.0302 & 1.4209 & 0.9797 & 1.5080 \\
\hline $95 \%$ & 0.5766 & 0.8124 & 0.7837 & 0.8828 & 0.5737 & 1.1304 & 0.5453 & 1.0895 \\
\hline $90 \%$ & 0.3894 & 0.6204 & 0.4665 & 0.5844 & 0.3265 & 0.8947 & 0.4165 & 0.8572 \\
\hline $75 \%$ & 0.1767 & 0.3689 & 0.1940 & 0.2887 & 0.1026 & 0.4696 & 0.1315 & 0.3001 \\
\hline Median & -0.0234 & 0.1477 & -0.0229 & 0.0913 & -0.0198 & 0.1235 & -0.0150 & 0.0850 \\
\hline $25 \%$ & -0.1555 & 0.0074 & -0.1666 & -0.0256 & -0.0933 & 0.0059 & -0.0901 & -0.0232 \\
\hline $10 \%$ & -0.2500 & -0.1169 & -0.2841 & -0.1316 & -0.1832 & -0.0590 & -0.1419 & -0.0840 \\
\hline $5 \%$ & -0.3494 & -0.1771 & -0.3900 & -0.2357 & -0.2371 & -0.1175 & -0.1907 & -0.1251 \\
\hline $1 \%$ & -0.6603 & -0.5136 & -0.8389 & -0.3783 & -0.5310 & -0.2331 & -0.2975 & -0.2347 \\
\hline \multicolumn{9}{|c|}{ Panel B. Performance Proportions } \\
\hline & & & & Small & Large & \multicolumn{2}{|c|}{ Value } & Growth \\
\hline \multicolumn{2}{|c|}{ Performance } & \multicolumn{2}{|c|}{$\% \alpha_{M F, S}>0$} & 45.85 & 76.59 & \multicolumn{2}{|c|}{47.32} & 68.29 \\
\hline \multicolumn{2}{|c|}{ Sign } & \multicolumn{2}{|c|}{$\% \alpha_{M F, S}<0$} & 54.15 & 23.41 & \multicolumn{2}{|c|}{52.68} & 31.71 \\
\hline
\end{tabular}

Note. This table shows statistics on the distribution of monthly SDF alphas for Other funds using the broad style SDFs. The columns labeled Small, Large, Value and Growth refer to results using, respectively, the Small, Large, Value and Growth SDFs for evaluation. The Other funds include funds classified into the Other style using a threshold for style inclusion of $25 \%$. Each fund is evaluated with all SDFs. Panel A provides the mean, standard deviation (StdDev) and selected percentiles of the distributions of alphas (columns under Performance) and their $t$-statistics (columns under $t$-statistics). It also reports the $t$-statistics ( $t$-stat) on the significance of the mean of alphas. Panel B gives the proportions of alphas that are positive $\left(\% \alpha_{M F, S}>0\right)$ and negative $\left(\% \alpha_{M F, S}<0\right)$. Results are in percentage except the $t$-statistics.

Table 10. Narrow style-clientele-specific alphas for other mutual funds

\begin{tabular}{|c|c|c|c|c|c|c|c|c|}
\hline \multicolumn{9}{|c|}{ Panel A. Performance and $t$-statistics } \\
\hline & \multicolumn{4}{|c|}{ Performance } & \multicolumn{4}{|c|}{$t$-statistics } \\
\hline & LCG & SCG & LCV & SCV & LCG & SCG & LCV & SCV \\
\hline Mean & 0.1191 & 0.0448 & -0.0672 & -0.0033 & 0.1518 & 0.0540 & 0.0121 & 0.0436 \\
\hline StdDev & 0.2738 & 0.2796 & 0.3372 & 0.2768 & 0.3097 & 0.2558 & 0.1763 & 0.2970 \\
\hline$(t$-stat $)$ & $(2.003)$ & $(0.727)$ & $(-0.900)$ & $(-0.051)$ & & & & \\
\hline $99 \%$ & 0.8198 & 0.7913 & 0.6493 & 0.7166 & 1.3977 & 1.0246 & 0.6872 & 1.2924 \\
\hline $95 \%$ & 0.7058 & 0.6142 & 0.4630 & 0.4867 & 0.7095 & 0.5838 & 0.3045 & 0.7216 \\
\hline $90 \%$ & 0.5011 & 0.4522 & 0.3748 & 0.3696 & 0.5724 & 0.3677 & 0.2230 & 0.3548 \\
\hline $75 \%$ & 0.2649 & 0.1930 & 0.1546 & 0.1653 & 0.2117 & 0.1091 & 0.0763 & 0.0958 \\
\hline Median & 0.0661 & -0.0074 & -0.0723 & -0.0584 & 0.0524 & -0.0051 & -0.0342 & -0.0339 \\
\hline $25 \%$ & -0.0498 & -0.1416 & -0.2516 & -0.1715 & -0.0313 & -0.0832 & -0.0997 & -0.0985 \\
\hline $10 \%$ & -0.1614 & -0.2344 & -0.4520 & -0.2880 & -0.0918 & -0.1459 & -0.1484 & -0.1802 \\
\hline $5 \%$ & -0.2236 & -0.3055 & -0.5962 & -0.3788 & -0.1282 & -0.2108 & -0.1805 & -0.2629 \\
\hline $1 \%$ & -0.5661 & -0.6056 & -1.1785 & -0.7413 & -0.2619 & -0.4817 & -0.2725 & -0.4295 \\
\hline \multicolumn{9}{|c|}{ Panel B. Performance Proportions } \\
\hline & & & & LCG & SCG & \multicolumn{2}{|c|}{$\mathrm{LCV}$} & SCV \\
\hline \multicolumn{2}{|c|}{ Performance } & \multicolumn{2}{|c|}{$\% \alpha_{M F, S}>0$} & 63.90 & 49.27 & \multicolumn{2}{|c|}{44.39} & 44.39 \\
\hline \multicolumn{2}{|c|}{ Sign } & \multicolumn{2}{|c|}{$\% \alpha_{M F, S}<0$} & 36.10 & 50.73 & \multicolumn{2}{|c|}{55.61} & 55.61 \\
\hline
\end{tabular}

Note. This table shows statistics on the distribution of monthly SDF alphas for Other funds using the narrow style SDFs. The columns labeled LCG, SCG, LCV and SCV refer to results using, respectively, the LCG, SCG, LCV and SCV SDFs for evaluation. The Other funds include funds classified into the Other style using a threshold for style inclusion of $25 \%$. Each fund is evaluated with all SDFs. Panel A provides the mean, standard deviation (StdDev) and selected percentiles of the distributions of alphas (columns under Performance) and their $t$-statistics (columns under $t$-statistics). It also reports the $t$-statistics ( $t$-stat) on the significance of the mean of alphas. Panel B gives the proportions of alphas that are positive $\left(\% \alpha_{M F, S}>0\right)$ and negative $\left(\% \alpha_{M F, S}<0\right)$. Results are in percentage except the $t$-statistics. 
Overall, tables 7 to 10 find that funds not assigned to clientele-specific styles have performance that depends on the SDFs used for evaluation. The mean values for Large, Growth and LCG clienteles are neutral for Mixed funds and significantly positive for Other funds. The mean values for Small, Value and LCV clienteles are significantly negative for Mixed funds and neutral for Other funds. Given the features of the SDFs, these results suggest that the performance of funds not attached to a particular clientele is, in general, negative (positive) for investors who are more (less) averse to difficult economic conditions and tend to be pessimist and contrarian (optimist and trend follower).

\subsection{Value Added with Style-Clientele-Specific Performance Measures}

This section studies the value added of the actively-managed fund industry from the perspective of the style clienteles by combining the categorized funds into a full-sample cross-section. In the style-clientele-specific evaluation, each individual fund is given multiple performance values. Each corner fund is evaluated with three SDFs, i.e., two broad style SDFs and one narrow style SDF. For example, a large-cap growth fund is evaluated with the Large, Growth and LCG SDFs. Each Mixed or Other fund is evaluated with the eight style SDFs. To obtain a full-sample cross-sectional distribution of alphas where each fund is only included once, we need to select one alpha per fund. Instead of subjectively picking one value, this section examines many distributions by considering either the minimum or maximum alpha for each fund, thus providing a range of performance cross-sections accounting for various clienteles.

Table 11. Value added from Style-Clientele-Specific Alphas with $\bar{\alpha}_{s}=0.15 \%$

\begin{tabular}{|c|c|c|c|c|c|c|c|c|}
\hline \multicolumn{9}{|c|}{ Panel A. Performance and $t$-statistics } \\
\hline & \multicolumn{4}{|c|}{ Performance } & \multicolumn{4}{|c|}{$t$-statistics } \\
\hline & \multicolumn{2}{|c|}{ Broad } & \multicolumn{2}{|c|}{ Narrow } & \multicolumn{2}{|c|}{ Broad } & \multicolumn{2}{|c|}{ Narrow } \\
\hline & Min & $\operatorname{Max}$ & Min & Max & Min & $\operatorname{Max}$ & Min & $\operatorname{Max}$ \\
\hline Mean & -0.1815 & 0.1747 & -0.2390 & 0.0742 & -0.0549 & 0.1990 & -0.0051 & 0.1793 \\
\hline $\begin{array}{l}\text { StdDev } \\
(t \text {-stat })\end{array}$ & $\begin{array}{c}0.3176 \\
(-2.713)\end{array}$ & $\begin{array}{l}0.3619 \\
(2.291)\end{array}$ & $\begin{array}{c}0.4230 \\
(-2.682)\end{array}$ & $\begin{array}{l}0.2901 \\
(1.213)\end{array}$ & 0.3402 & 0.4318 & 0.4068 & 0.5528 \\
\hline $99 \%$ & 0.5515 & 1.1269 & 0.6099 & 0.8022 & 1.1999 & 1.6782 & 1.6256 & 2.0360 \\
\hline $95 \%$ & 0.2970 & 0.8136 & 0.3491 & 0.5355 & 0.4849 & 0.8980 & 0.7328 & 1.2565 \\
\hline $90 \%$ & 0.1735 & 0.6339 & 0.2027 & 0.4219 & 0.2017 & 0.6773 & 0.3788 & 0.7883 \\
\hline $75 \%$ & -0.0040 & 0.3722 & 0.0145 & 0.2251 & -0.0022 & 0.3744 & 0.0102 & 0.3503 \\
\hline Median & -0.1762 & 0.1248 & -0.1966 & 0.0615 & -0.0888 & 0.1542 & -0.0901 & 0.0830 \\
\hline $25 \%$ & -0.3354 & -0.0555 & -0.4213 & -0.0758 & -0.1541 & -0.0491 & -0.1501 & -0.0882 \\
\hline $10 \%$ & -0.5375 & -0.1923 & -0.7227 & -0.2401 & -0.2461 & -0.1803 & -0.2290 & -0.2772 \\
\hline $5 \%$ & -0.6890 & -0.3076 & -0.9554 & -0.3471 & -0.3653 & -0.3138 & -0.3410 & -0.4646 \\
\hline $1 \%$ & -1.0662 & -0.5596 & -1.7217 & -0.6794 & -1.0649 & -0.7693 & -0.9274 & -1.2388 \\
\hline \multicolumn{9}{|c|}{ Panel B. Performance Proportions } \\
\hline & & & & \multicolumn{2}{|c|}{ Broad } & \multicolumn{3}{|c|}{ Narrow } \\
\hline & & & & Min & Max & \multicolumn{2}{|c|}{ Min } & Max \\
\hline \multicolumn{2}{|c|}{ Performance } & \multicolumn{2}{|c|}{$\% \alpha_{M F, S}>\alpha_{M F, F F}$} & 24.74 & 76.84 & \multicolumn{2}{|c|}{29.72} & 77.47 \\
\hline \multicolumn{2}{|c|}{ Sign } & \multicolumn{2}{|c|}{$\% \alpha_{M F, S}<\alpha_{M F F F}$} & 75.26 & 23.16 & \multicolumn{2}{|c|}{70.28} & 22.53 \\
\hline
\end{tabular}

Note. This table shows statistics on the distributions of monthly SDF alphas for the full sample of funds using the broad and narrow style SDFs estimated with an upper performance bound for the style portfolios of $0.15 \%$. The columns labeled Broad and Narrow refer to results using, respectively, the broad style (Small, Large, Value, Growth) SDFs and the narrow style (LCG, SCG, LCV and SCV) SDFs for evaluation. The distributions consider either the minimum (Min) alpha or the maximum (Max) alpha for each fund evaluated by multiple SDFs. Panel A provides the mean, standard deviation (StdDev) and selected percentiles of the distributions of alphas (columns under Performance) and their $t$-statistics (columns under $t$-statistics). It also reports the $t$-statistics ( $t$-stat) on the significance of the mean of alphas. Panel B reports proportions of style-clientele-specific alphas that are larger $\left(\% \alpha_{M F, S}>\alpha_{M F, F F}\right)$ and smaller $\left(\% \alpha_{M F, S}<\alpha_{M F, F F}\right)$ than the Fama-French SDF alphas. Results are in percentage except the $t$-statistics.

Table 11 presents the results for the minimum (Min) and maximum (Max) alpha distributions, with funds evaluated either with the broad style SDFs (columns under Broad) or the narrow style SDFs (columns under Narrow). Figure 3 illustrates these distributions. As in tables 5 to 10, panel A provides statistics on the distributions of the estimated SDF alphas (columns under Performance) and their corresponding $t$-statistics (columns under $t$-statistics), including the $t$-statistics ( $t$-stat) on the significance of the cross-sectional mean of 
estimated alphas. In panel $\mathrm{B}$, instead of providing proportions of positive and negative alphas as in previous tables, we report the proportions of estimated alphas that are larger $\left(\% \alpha_{M F, S}>\alpha_{M F, F F}\right)$ and smaller $\left(\% \alpha_{M F, S}<\right.$ $\alpha_{M F, F F}$ ) than the estimated Fama-French alphas (given in table 1), which allow us to compare the value added for style clienteles to the value added from a widely-used model.

(a)

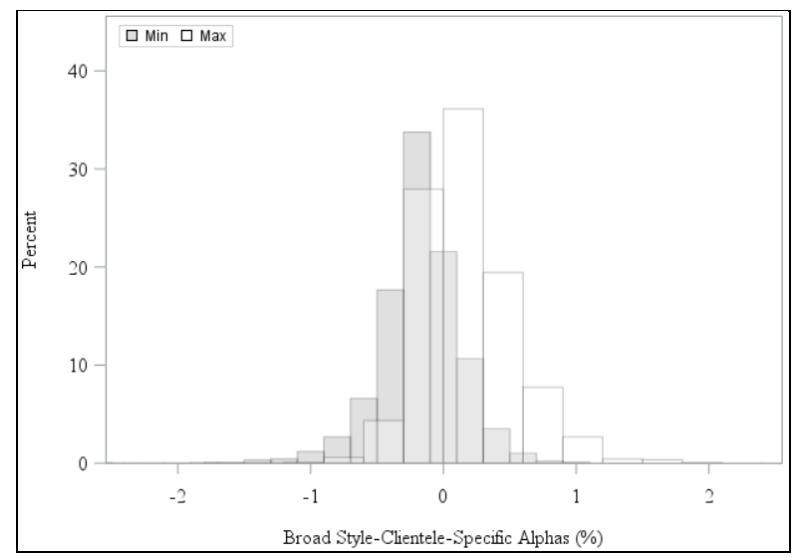

(b)

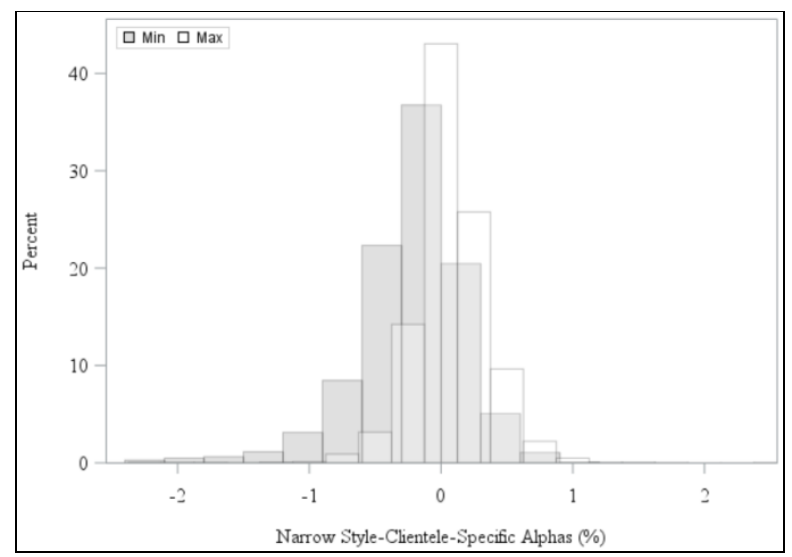

Figure 3. Histograms of Style-Clientele-Specific Alphas

Note. This figure presents histograms illustrating the distributions of the minimum (Min) style-clientele-specific alphas and maximum (Max) style-clientele-specific alphas evaluated with the broad style SDFs (figure 3a) and the narrow style SDFs (figure 3b).

The results show that the sign of the value added by the fund industry is ambiguous and depends on the choice of measures. The minimum broad and narrow style-clientele-specific alpha estimates show a negative average performance of $-0.182 \%(t$-stat. $=-2.71)$ and $-0.239 \%(t$-stat. $=-2.68)$, respectively, and are below the Fama-French alphas for more than $70 \%$ of funds. In contrast, the maximum broad and narrow style-clientele-specific alpha estimates show a positive average performance of $0.174 \%(t$-stat. $=2.29)$ and $0.074 \%$ $(t$-stat. $=1.21)$, respectively, and are above the Fama-French alphas for more than $75 \%$ of funds. The disagreement in alpha is well illustrated by the alpha distributions in figure 3. Overall, these findings suggest that the different rational and behavioral features of the style SDFs can be important determinants of the value added by the fund industry in a clientele-specific performance evaluation.

\subsection{Sensitivity of Value Added Results to Upper Performance Bound Choice}

Our empirical results have thus far relied on the style SDFs identified with an upper performance bound for the style portfolios of $\bar{\alpha}_{s}=0.15 \%$, which is consistent with the findings of FL. This section examines the sensitivity of our results to this choice by considering values of $\bar{\alpha}_{s}=0 \%$ and $\bar{\alpha}_{s}=0.3 \%$. These values respectively assume that the style clienteles expect either no performance or a relatively high performance from their preferred style portfolios.

Tables 12 and 13 reproduce the value added results of table 11 by using $\bar{\alpha}_{s}=0 \%$ and $\bar{\alpha}_{s}=0.3 \%$, respectively. The tables show that the investor disagreement observed from the difference between the minimum and maximum alphas increases with the upper performance bound. Furthermore, this increase is caused by movements in the maximum alpha distributions. Specifically, the results for the minimum alpha distributions are similar to those in table 11, including comparable negative mean alphas and high proportions of clientele-specific alphas below the Fama-French alphas. In contrast, the results for the maximum alpha distributions are relatively neutral when $\bar{\alpha}_{s}=0 \%$, but more positive when $\bar{\alpha}_{S}=0.3 \%$ than when $\bar{\alpha}_{S}=0.15 \%$. When $\bar{\alpha}_{s}=0 \%$, the maximum alpha estimates have insignificant means and are above the Fama-French alphas for only an average of $55 \%$ of funds. When $\bar{\alpha}_{s}=0.3 \%$, the maximum alpha estimates have highly statistically significant means and are above the Fama-French alphas for $85 \%$ of funds. 
Table 12. Value added from Style-Clientele-Specific Alphas with $\bar{\alpha}_{s}=0 \%$

\begin{tabular}{|c|c|c|c|c|c|c|c|c|}
\hline \multicolumn{9}{|c|}{ Panel A. Performance and $t$-statistics } \\
\hline \multicolumn{5}{|c|}{$\begin{array}{lr} & \text { Performance } \\
\end{array}$} & \multicolumn{4}{|c|}{$t$-statistics } \\
\hline & \multicolumn{2}{|c|}{ Broad } & \multicolumn{2}{|c|}{ Narrow } & \multicolumn{2}{|c|}{ Broad } & \multicolumn{2}{|c|}{ Narrow } \\
\hline & Min & $\operatorname{Max}$ & Min & Max & Min & Max & Min & Max \\
\hline Mean & -0.1879 & 0.0241 & -0.2144 & -0.0379 & -0.1366 & 0.0057 & -0.1391 & -0.0714 \\
\hline StdDev & 0.2795 & 0.2919 & 0.3187 & 0.2657 & 0.3562 & 0.3654 & 0.4146 & 0.5062 \\
\hline$(t$-stat $)$ & $(-3.192)$ & $(0.391)$ & $(-3.194)$ & $(-0.676)$ & & & & \\
\hline $99 \%$ & 0.4166 & 0.8193 & 0.4261 & 0.5991 & 0.7400 & 1.1523 & 0.9709 & 1.2921 \\
\hline $95 \%$ & 0.2071 & 0.5272 & 0.2224 & 0.3687 & 0.2225 & 0.5165 & 0.3007 & 0.6990 \\
\hline $90 \%$ & 0.1135 & 0.3667 & 0.1031 & 0.2607 & 0.0956 & 0.3524 & 0.1259 & 0.3899 \\
\hline $75 \%$ & -0.0335 & 0.1745 & -0.0408 & 0.1059 & -0.0212 & 0.1587 & -0.0277 & 0.1362 \\
\hline Median & -0.1727 & -0.0036 & -0.1782 & -0.0448 & -0.0905 & -0.0049 & -0.0884 & -0.0544 \\
\hline $25 \%$ & -0.3101 & -0.1374 & -0.3409 & -0.1658 & -0.1773 & -0.1430 & -0.1682 & -0.2287 \\
\hline $10 \%$ & -0.4901 & -0.2702 & -0.5607 & -0.3211 & -0.4040 & -0.3089 & -0.4492 & -0.5451 \\
\hline $5 \%$ & -0.6349 & -0.3848 & -0.7430 & -0.4460 & -0.7124 & -0.4758 & -0.8764 & -0.8994 \\
\hline $1 \%$ & -0.9977 & -0.6738 & -1.2508 & -0.7611 & -1.5960 & -1.1743 & -1.8776 & -1.8776 \\
\hline \multicolumn{9}{|c|}{ Panel B. Performance Proportions } \\
\hline & & & & \multicolumn{2}{|c|}{ Broad } & \multicolumn{3}{|c|}{ Narrow } \\
\hline & & & & Min & Max & \multicolumn{2}{|c|}{ Min } & $\operatorname{Max}$ \\
\hline \multirow{2}{*}{\multicolumn{2}{|c|}{$\begin{array}{l}\text { Performance } \\
\quad \text { Sign }\end{array}$}} & \multicolumn{2}{|c|}{$\% \alpha_{M F, S}>\alpha_{M F, F F}$} & 16.44 & 58.62 & \multicolumn{2}{|c|}{21.62} & 52.89 \\
\hline & & $\% \alpha_{M}$ & $<\alpha_{M F, F F}$ & 83.56 & 41.38 & \multicolumn{2}{|c|}{78.38} & 47.11 \\
\hline
\end{tabular}

Note. Table 12 shows statistics on the distributions of monthly SDF alphas for the full sample of funds using the broad and narrow style SDFs estimated with an upper performance bound for the style portfolios of $0 \%$. The columns labeled Broad and Narrow refer to results using, respectively, the broad style (Small, Large, Value, Growth) SDFs and the narrow style (LCG, SCG, LCV and SCV) SDFs for evaluation. The distributions consider either the minimum (Min) alpha or the maximum (Max) alpha for each fund evaluated by multiple SDFs. Panel A provides the mean, standard deviation (StdDev) and selected percentiles of the distributions of alphas (columns under Performance) and their corresponding $t$-statistics (columns under $t$-statistics). It also reports the $t$-statistics ( $t$-stat) on the significance of the mean of alphas. Panel B reports proportions of style-clientele-specific alphas that are larger $\left(\% \alpha_{M F, S}>\alpha_{M F, F F}\right)$ and smaller $\left(\% \alpha_{M F, S}<\right.$ $\alpha_{M F, F F}$ ) than the Fama-French SDF alphas. Results are in percentage except the $t$-statistics.

Table 13. Value added from Style-Clientele-Specific Alphas with $\bar{\alpha}_{s}=0.3 \%$

\begin{tabular}{|c|c|c|c|c|c|c|c|c|}
\hline \multicolumn{9}{|c|}{ Panel A. Performance and $t$-statistics } \\
\hline \multicolumn{5}{|c|}{$\begin{array}{ll} & \text { Performance } \\
\end{array}$} & \multicolumn{4}{|c|}{$t$-statistics } \\
\hline & \multicolumn{2}{|c|}{ Broad } & \multicolumn{2}{|c|}{ Narrow } & \multicolumn{2}{|c|}{ Broad } & \multicolumn{2}{|c|}{ Narrow } \\
\hline & Min & $\operatorname{Max}$ & Min & Max & Min & Max & Min & Max \\
\hline Mean & -0.1776 & 0.3286 & -0.2666 & 0.1867 & 0.0068 & 0.3883 & 0.1062 & 0.4240 \\
\hline $\begin{array}{c}\text { StdDev } \\
(t \text {-stat })\end{array}$ & $\begin{array}{r}0.3739 \\
(-2.254) \\
\end{array}$ & $\begin{array}{l}0.4479 \\
(3.482) \\
\end{array}$ & $\begin{array}{c}0.5518 \\
(-2.293) \\
\end{array}$ & $\begin{array}{l}0.3272 \\
(2.708)\end{array}$ & 0.4161 & 0.5453 & 0.5730 & 0.7010 \\
\hline $99 \%$ & 0.7143 & 1.5232 & 0.7855 & 1.0721 & 1.7479 & 2.3055 & 2.3873 & 2.8530 \\
\hline $95 \%$ & 0.4091 & 1.1125 & 0.4931 & 0.7196 & 0.8015 & 1.3792 & 1.3925 & 1.8727 \\
\hline $90 \%$ & 0.2584 & 0.9113 & 0.3306 & 0.5843 & 0.3783 & 0.9901 & 0.8052 & 1.2919 \\
\hline $75 \%$ & 0.0398 & 0.5770 & 0.0841 & 0.3493 & 0.0283 & 0.5955 & 0.0959 & 0.6628 \\
\hline Median & -0.1836 & 0.2623 & -0.2167 & 0.1644 & -0.0912 & 0.3220 & -0.0991 & 0.2343 \\
\hline $25 \%$ & -0.3705 & 0.0136 & -0.5034 & 0.0041 & -0.1561 & 0.0112 & -0.1678 & 0.0037 \\
\hline $10 \%$ & -0.5977 & -0.1222 & -0.9096 & -0.1671 & -0.2326 & -0.1041 & -0.2301 & -0.1499 \\
\hline $5 \%$ & -0.7628 & -0.2465 & -1.2201 & -0.2795 & -0.2941 & -0.2036 & -0.2779 & -0.2845 \\
\hline $1 \%$ & -1.2292 & -0.5169 & -2.3046 & -0.5725 & -0.7409 & -0.4741 & -0.6018 & -0.8388 \\
\hline \multicolumn{9}{|c|}{ Panel B. Performance Proportions } \\
\hline & & & & \multicolumn{2}{|c|}{ Broad } & \multicolumn{3}{|c|}{ Narrow } \\
\hline & & & & Min & $\operatorname{Max}$ & \multicolumn{2}{|c|}{ Min } & Max \\
\hline \multirow{2}{*}{\multicolumn{2}{|c|}{$\begin{array}{l}\text { Performance } \\
\text { Sign }\end{array}$}} & \multirow{2}{*}{\multicolumn{2}{|c|}{$\begin{array}{l}\% \alpha_{M F, S}>\alpha_{M F, F F} \\
\% \alpha_{M F S}<\alpha_{M F F F}\end{array}$}} & 29.05 & 86.32 & \multicolumn{2}{|c|}{31.66} & 88.42 \\
\hline & & & & 70.95 & 13.68 & \multicolumn{2}{|c|}{68.34} & 11.58 \\
\hline
\end{tabular}

Note. Table 13 shows statistics on the distributions of monthly SDF alphas for the full sample of funds using the broad and narrow style SDFs estimated with an upper performance bound for the style portfolios of $0.3 \%$. The columns labeled Broad and Narrow refer to results using, respectively, the broad style (Small, Large, Value, Growth) SDFs and the narrow style (LCG, SCG, LCV and SCV) SDFs for evaluation. The distributions consider either the minimum (Min) alpha or the maximum (Max) alpha for each fund evaluated by multiple SDFs. Panel A provides the mean, standard deviation (StdDev) and selected percentiles of the distributions of alphas (columns under Performance) and their $t$-statistics (columns under $t$-statistics). It also reports the $t$-statistics ( $t$-stat) on the significance of the mean of alphas. Panel B reports proportions of style-clientele-specific alphas that are larger $\left(\% \alpha_{M F, S}>\alpha_{M F, F F}\right)$ and smaller $\left(\% \alpha_{M F, S}<\alpha_{M F, F F}\right)$ than the Fama-French SDF alphas. Results are in percentage except the $t$-statistics. 
Overall, these results confirm that the sign of the value added by the fund industry is generally ambiguous and depends on the choice of clienteles. But they also show that it partly depends on the maximum performance expected by the clienteles most favorable to the style.

\section{Conclusion}

Mutual funds cater to and attract specific clienteles throughout their investment style. We propose clientele-specific performance measures based on the implied style preferences of mutual fund investors. The performance framework is based on a SDF alpha approach with investor disagreement, following CK. The identification of meaningful SDFs for style clienteles uses representative style portfolios and the findings of FL on investor disagreement. The style classification employs a method to exploit existing objective code data from Lipper and to account for code changes and missing codes.

Our empirical investigation uses a sample of 2530 U.S. equity mutual funds with monthly returns from 1998 to 2012. The economic properties of the estimated SDFs indicate that the implied style preferences have different rational and behavioral features. Value and small-cap SDFs show large aversion to difficult economic conditions, pessimism and contrarian behavior. Growth and large-cap SDFs show low aversion to difficult economic conditions, optimism and trend following behavior. The style-clientele-specific evaluation finds that funds assigned to styles have a neutral to positive performance when evaluated with their relevant clientele-specific measures. The performance of the other funds is sensitive to the clienteles, and the rational and behavioral features of the SDFs are important determinants. The value added by the mutual fund industry also depends on the choice of measures. Overall, we find that implied preferences and alphas differ for size and value mutual fund clienteles. We provide supporting evidence for the conjecture of Ferson (2010) that clientele-specific measures based on meaningful clienteles might be necessary to evaluate properly managed portfolios.

Overall, our empirical results suggest that considering relevant clientele-specific SDFs and focusing on clientele-specific evaluation leads to more positive performance when funds are evaluated with their related style-clientele-specific measure. These results support the conjecture of Ferson (2010) that clientele-specific measures based on meaningful clienteles might be necessary to evaluate properly managed funds.

There is a need for more research on clientele effects in performance evaluation. Our clientele-specific performance approach can serve as a useful framework for developing measures to account for other clientele effects documented by the literature. Future research can also employ different techniques to better characterize the economic properties of preferences implied by the clientele SDFs. Finally, other strategies based on different restrictions or alternative incomplete market setups can be followed to identify economically meaningful SDFs useful for clientele-specific measurement.

\section{Acknowledgments}

We thank Vikas Agarwal, Laurent Barras, Marie-Claude Beaulieu, Geert Bekaert, Frank Coggins, Wayne Ferson, Ali Ghali, Abigail Hornstein, Murali Jagannathan, Jerchern Lin, Gabriel Power, Jeffrey Wurgler, Ilkner Zer Boudet and participants at the PFMC 2017 Conference in Paris, France, 2016 FMA Annual Meeting in Las Vegas, NV, SCSE 2016 Annual Meeting in Quebec City, Canada, and at a seminar at Laval University for helpful comments. We acknowledge financial support from the Social Sciences and Humanities Research Council, Institut de Finance Mathématique de Montréal, the Département des sciences administratives at Université du Québec en Outaouais and the Faculty of Business Administration and IG Wealth Management Chair in Financial Planning at Laval University.

\section{References}

Ahn, D., Cao, H. H., \& Chrétien, S. (2009). Portfolio performance measurement: A no arbitrage bounds $\begin{array}{lllll}\text { approach. } \quad \text { European } & \text { Financial 298-339. }\end{array}$ https://doi.org/10.1111/j.1468-036X.2009.00480.x

Bailey, W., Kumar, A., \& Ng, D. (2011). Behavioral biases and mutual fund investors. Journal of Financial Economics, 102, 1-27. https://doi.org/10.1016/j.jfineco.2011.05.002

Baker, J., \& Wurgler, J. (2006). Investor sentiment and the cross-section of stock returns. Journal of Finance, 61, 1645-1680. https://doi.org/10.1111/j.1540-6261.2006.00885.x

Baker, J., \& Wurgler, J. (2007) Investor sentiment in the stock market. Journal of Economic Perspectives, 21, 129-151. https://doi.org/10.1257/jep.21.2.129

Bansal, R., \& Viswanathan, S. (1993). No-arbitrage and arbitrage pricing: A new approach. Journal of Finance, 48, 1231-1262. https://doi.org/10.1111/j.1540-6261.1993.tb04753.x 
Bansal, R., \& Yaron, A. (2004) Risks for the long run: A potential resolution of asset pricing puzzles. Journal of Finance, 59, 1481-1509. https://doi.org/10.1111/j.1540-6261.2004.00670.x

Barber, B. M., Odean, T., \& Zheng, L. (2005). Out of sight, out of mind: The effects of expenses on mutual fund flows. Journal of Business, 78, 2095-2120. https://doi.org/10.1086/497042

Barberis, N., \& Shleifer, A. (2003). Style investing. Journal of Financial Economics, 68, 161-199. http://dx.doi.org/10.1016/S0304-405X(03)00064-3

Barras, L., Scaillet, O., \& Wermers, R. (2010). False discoveries in mutual fund performance: Measuring luck in estimated alphas. Journal of Finance, 65, 179-216. https://doi.org/10.1111/j.1540-6261.2009.01527.x

Bergstresser, D., Chalmers, J., \& Tufano, P. (2009). Assessing the costs and benefits of brokers in the mutual fund industry. Review of Financial Studies, 22, 4129-4156. https://doi.org/10.1093/rfs/hhp022

Berk, J. B., \& Green, R. C. (2004). Mutual fund flows and performance in rational markets. Journal of Political Economy, 112, 1269-1295. https://doi.org/10.1086/424739

Berk, J. B., \& van Binsbergen, J. H. (2015). Measuring skill in the mutual fund industry. Journal of Financial Economics, 118, 1-20. https://doi.org/10.1016/j.jfineco.2015.05.002

Betermier, S., Calvet, L. E., \& Sodini, P. (2017). Who are value and growth investors? Journal of Finance, 72, 5-46. https://doi.org/10.1111/jofi.12473

Blackburn, D. W., Goetzmann, W. N., \& Ukhov, A. D. (2014). Is trading behavior stable across contexts? Evidence from style and multi-style investors. Quantitative Finance, 14, 605-627. https://doi.org/10.1080/14697688.2013.797595

Bondarenko, O. (2003). Statistical arbitrage and securities prices. Review of Financial Studies, 16, 875-919. https://doi.org/10.1093/rfs/hhg016

Boyer, B. H. (2011). Style-related comovement: Fundamentals or labels? Journal of Finance, 66, 307-332. https://doi.org/10.1111/j.1540-6261.2010.01633.x

Brown, S. J., \& Goetzmann, W. N. (1997). Mutual fund styles. Journal of Financial Economics, 43, 373-399. https://doi.org/10.1016/S0304-405X(96)00898-7

Cao, C, Iliev, P., \& Velthius, R. (2017). Style drift: Evidence from small-cap mutual funds. Journal of Banking and Finance, 78, 42-57. https://doi.org/10.1016/j.jbankfin.2017.01.009

Chan, L. K. C., Chen, H. L., \& Lakonishok, J. (2002). On mutual fund investment styles. Review of Financial Studies, 15, 1407-1437. https://doi.org/10.1093/rfs/15.5.1407

Chapman, D. A. (1997). Approximating the asset pricing kernel. Journal of Finance, 52, 1383-1410. https://doi.org/10.1111/j.1540-6261.1997.tb01114.x

Chen, Z., \& Knez, P. J. (1996). Portfolio performance measurement: Theory and applications. Review of Financial Studies, 9, 511-555. https://doi.org/10.1093/rfs/9.2.511

Chrétien, S. (2012). Bounds on the autocorrelation of admissible stochastic discount factors. Journal of Banking and Finance, 36, 1943-1962. https://doi.org/10.1016/j.jbankfin.2012.03.002

Chrétien, S., \& Kammoun, M. (2017). Mutual fund performance evaluation and best clienteles. Journal of Financial and Quantitative Analysis, 52, 1577-1604. https://doi.org/10.1017/S002210901700045X

Chrétien, S., \& Kammoun, M. (2018). Representative investors versus best clienteles: Performance evaluation disagreement in mutual funds. Working paper, SSRN. https://dx.doi.org/10.2139/ssrn.2977656

Cochrane, J., \& Saá-Requejo, J. (2000). Beyond arbitrage: Good-deal asset price bounds in incomplete markets. Journal of Political Economy, 108, 79-119. https://doi.org/10.1086/262112

Cooper, M. J., Gulen, H., \& Rau, P. R. (2005). Changing names with style: Mutual fund name changes and their effects on fund flows. Journal of Finance, 65, 2825-2858. https://doi.org/10.1111/j.1540-6261.2005.00818.x

Cronqvist, H., Siegel, S. \& Yu, F. (2015). Value versus growth investing: Why do different investors have

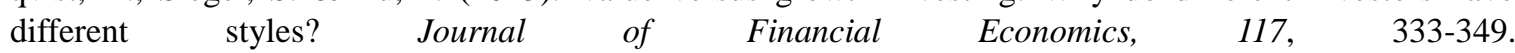
https://doi.org/10.1016/j.jfineco.2015.04.006

Dahlquist, M., \& Söderlind, P. (1999). Evaluating portfolio performance with stochastic discount factors. Journal of Business, 72, 347-383. https://doi.org/10.1086/209618

Dechow, P. M., \& Sloan, R. G. (1997). Returns to contrarian investment strategies: Tests of naïve expectations 
hypotheses. Journal of Financial Economics, 43, 3-27. https://doi.org/10.1016/S0304-405X(96)00887-2

Del Guercio, D., \& Reuter, J. (2014). Mutual fund performance and the incentive to generate alpha. Journal of Finance, 69, 1673-1704. https://doi.org/10.1111/jofi.12048

Dibartolomeo, D., \& Witkowski, E. (1997). Mutual fund misclassification: Evidence based on style analysis. Financial Analysts Journal, 53, 32-43. https://doi.org/10.2469/faj.v53.n5.2115

Dittmar, R. (2002). Nonlinear pricing kernels, kurtosis preferences and the cross-section of equity returns. Journal of Finance, 57, 369-403. https://doi.org/10.1111/1540-6261.00425

Doukas, J. A., Kim, C., \& Pantzalis, C. (2002). A test of the errors-in-expectations explanation of the value/glamour stock returns performance: Evidence from analysts' forecasts. Journal of Finance, 57, 2143-2165. https://doi.org/10.1111/1540-6261.00491

Elton, E. J., Gruber, M. J., \& Blake, C. R. (2001). A first look at the accuracy of the CRSP mutual fund database and a comparison of the CRSP and Morningstar mutual fund databases. Journal of Finance, 56, 2415-2430. https://doi.org/10.1111/0022-1082.00410

Evans, R. B. (2010). Mutual fund incubation. Journal of Finance, 65, 1581-1611. https://doi.org/10.1111/j.1540-6261.2010.01579.x

Fama, E. F., \& French, K. R. (1992). The cross-section of expected stock returns. Journal of Finance, 47, 427-465. https://doi.org/10.1111/j.1540-6261.1992.tb04398.x

Fama, E. F., \& French, K. R. (1993). Common risk factors in the returns on stocks and bonds. Journal of Financial Economics, 33, 3-56. https://doi.org/10.1016/0304-405X(93)90023-5

Fama, E. F., \& French, K. R. (1996). Multifactor explanations of asset pricing anomalies. Journal of Finance, 51, 1975-1999. https://doi.org/10.1111/j.1540-6261.1996.tb05202.x

Fama, E. F., \& French, K. R. (2010). Luck versus skill in the cross-section of mutual fund returns. Journal of Finance, 65, 1915-1948. https://doi.org/10.1111/j.1540-6261.2010.01598.x

Farnsworth, H., Ferson, W. E., Jackson, D., \& Todd, S. (2002). Performance evaluation with stochastic discount factors. Journal of Business, 75, 473-503. https://doi.org/10.1086/339902

Ferson, W. E. (2010). Investment performance evaluation. Annual Review of Financial Economics, 2, 207-234. https://doi.org/10.1146/annurev-financial-120209-134007

Ferson, W. E., \& Chen, Y. (2015). How many good and bad fund managers are there, really? Working paper, University of Southern California and Texas A\&M University.

Ferson, W. E., \& Lin, J. (2014). Alpha and performance measurement: The effect of investor heterogeneity. Journal of Finance, 69, 1565-1596. https://doi.org/10.1111/jofi.12165

Gârleanu, N., Kogan, L., \& Panageas, S. (2012). Displacement risk and asset returns. Journal of Financial Economics, 105, 491-510. https://doi.org/10.1016/j.jfineco.2012.04.002

Glosten, L., \& Jagannathan, R. (1994). A contingent claims approach to performance evaluation. Journal of Empirical Finance, 1, 133-66. https://doi.org/10.1016/0927-5398(94)90001-9

Gruber, M. J. (1996). Another puzzle: The growth in actively managed mutual funds. Journal of Finance, 51, 783-810. https://doi.org/10.1111/j.1540-6261.1996.tb02707.x

Hansen, L. P. (1982). Large sample properties of generalized method of moments estimators. Econometrica, 50, 1029-1054. https://doi.org/0012-9682(198207)50:4\%3C1029:LSPOGM\%3E2.0.CO;2-O

Hansen, L. P., \& Jagannathan, R. (1991). Implication of security market data for models of dynamic economies. Journal of Political Economy, 99, 225-262. https://doi.org/10.1086/261749

Huang, D., Jiang, F., Tu, J., \& Zhou, G. (2015). Investor sentiment aligned: A powerful predictor of stock returns. Review of Financial Studies, 28, 791-837. https://doi.org/10.1093/rfs/hhu080

Ivković, Z., \& Weisbenner, S. (2009). Individual investors mutual fund flows. Journal of Financial Economics, 92, 223-237. https://doi.org/10.1016/j.jfineco.2008.05.003

Jagannathan, R., \& Wang, Z. (1996). The conditional CAPM and the cross-section of expected returns. Journal of Finance, 51, 3-53. https://doi.org/10.1111/j.1540-6261.1996.tb05201.x

James, C., \& Karceski, J. (2006). Investor monitoring and differences in mutual fund performance. Journal of Banking and Finance, 30, 2787-2808. https://doi.org/10.1016/j.jbankfin.2005.11.003 
Jurado, K., Ludvigson, S. C., \& Ng, S. (2015). Measuring uncertainty. American Economic Review, 105, 1177-1216. https://doi.org/10.1257/aer.20131193

Jurek, J. W., \& Viceira, L. M. (2011). Optimal value and growth tilts in long-horizon portfolios. Review of Finance, 15, 29-74. https://doi.org/10.1093/rof/rfq013

Kacperczyk, M., Sialm, C., \& Zheng, L. (2008). Unobserved actions of mutual funds. Review of Financial Studies, 21, 2379-2416. https://doi.org/10.1093/rfs/hhl041

Kumar, A. (2009). Dynamic style preferences of individual investors and stock returns. Journal of Financial and Quantitative Analysis, 44, 607-640. https://doi.org/10.1017/S0022109009990020

La Porta, R. (1996). Expectations and the cross-section of stock returns. Journal of Finance, 51, 1715-1742. https://doi.org/10.1111/j.1540-6261.1996.tb05223.x

La Porta, R., Lakonishok, J., Shleifer, A., \& Vishny, R. W. (1997). Good news for value stocks: Further evidence on market efficiency. Journal of Finance, 52, 859-874. https://doi.org/10.1111/j.1540-6261.1997.tb04825.x

Lakonishok, J., Shleifer, A., \& Vishny, R.W. (1994). Contrarian investment, extrapolation, and risk. Journal of Finance, 49, 1541-1578. https://doi.org/10.1111/j.1540-6261.1994.tb04772.x

Liew, J., \& Vassalou, M. (2000). Can book-to-market, size, and momentum be risk factors that predict economic growth? Journal of Financial Economics, 57, 221-245. https://doi.org/10.1016/S0304-405X(00)00056-8

Lynch, A. W. (2001). Portfolio choice and equity characteristics: Characterizing the hedging demands induced by $\begin{array}{lllll}\text { return predictability. Journal of Financial Economics, 62, } & \text { 67-130. }\end{array}$ https://doi.org/10.1016/S0304-405X(01)00074-5

Malloy, C., \& Zhu, N. (2004). Mutual fund choices and investor demographics. Working paper, University of California at Davis.

Nanda, V., Narayanan, M. P., \& Warther, V. (2000). Liquidity, investment ability, and mutual fund structure. Journal of Financial Economics, 57, 417-443. https://doi.org/10.1016/S0304-405X(00)00063-5

Newey, W. K., \& West, K. D. (1987). A simple, positive semi-definite, heteroskedasticity and autocorrelation $\begin{array}{llll}\text { consistent } \quad \text { covariance } & \text { matrix. }\end{array}$ https://doi.org/0012-9682(198705)55:3<3C703:ASPSHA>3E2.0.CO;2-F

Pástor, Ĺ., \& Stambaugh, R. (2002). Mutual fund performance and seemingly unrelated assets. Journal of Financial Economics, 63, 315-349. https://doi.org/10.1016/S0304-405X(02)00064-8

Piotroski, J. D., \& So, E. C. (2012). Identifying expectation errors in value/glamour strategies: A fundamental analysis approach. Journal of Financial Economics, 25, 2841-2875. https://doi.org/10.1093/rfs/hhs061

Rosenberg, J. V., \& Engle, R. F. (2002). Empirical pricing kernel. Journal of Financial Economics, 64, 341-372. https://doi.org/10.1016/S0304-405X(02)00128-9

Sensoy, B. A. (2009). Performance evaluation and self-designated benchmark indexes in the mutual fund industry. Journal of Financial Economics, 92, 25-39. https://doi.org/10.1016/j.jfineco.2008.02.011

Sharpe, W. F. (1992). Asset allocation: management style and performance measurement. Journal of Portfolio Management, 18, 7-19. https://doi.org/10.3905/jpm.1992.409394

Shefrin, H. (2008). A Behavioral Approach to Asset Pricing (2nd ed.). Academic Press Advanced Finance Series: Elsevier.

Shefrin, H. (2009). Behavioralizing finance. Foundations and Trends in Finance, 4(1-2), 1-184. http://dx.doi.org/10.1561/0500000030

Shefrin, H. (2015). Investors' judgments, asset pricing factors and sentiment. European Financial Management, 2, 205-227. https://doi.org/10.1111/eufm.12059

Shefrin, H., \& Statman, M. (1995). Making sense of beta, size and book-to-market. Journal of Portfolio Management, 21, 26-34. https://doi.org/10.3905/jpm.1995.409506

Shefrin, H., \& Statman, M. (2003). The style of investor expectations. In T. Coggin, \& F. Fabozzi (Eds.), Handbook of Equity Style Management (pp. 195-218).

Teo, M., \& Woo, S. J. (2004). Style effects in the cross-section of stock returns. Journal of Financial Economics, 74, 367-398. https://doi.org/10.1016/j.jfineco.2003.10.003

Wahal, S., \& Yavuz, M. D. (2013). Style investing, comovement and return predictability. Journal of Financial 
Economics, 107, 136-154. https://doi.org/10.1016/j.jfineco.2012.08.005

Walkshausl, C. (2017). Expectation errors in European value-growth strategies. Review of Finance, 21, 845-870. https://doi.org/10.1093/rof/rfw012

\section{Notes}

Note 1. Other clientele effects have been documented in mutual funds in relation to behavioral biases (Barber, Odean, \& Zheng, 2005; Bailey, Kumar, \& Ng, 2011), demographics and investor sophistication (Malloy \& Zhu, 2004; Bailey et al., 2011), investor monitoring and investment advice (James and Karceski 2006; Bergstresser, Chalmers, \& Tufano, 2009; Del Guercio \& Reuter, 2014), liquidity service (Nanda, Narayanan, \& Warther, 2000), and taxation (Ivković \& Weisbenner, 2009).

Note 2. There is also related literature that examines the classification of funds according to their styles and the impact of fund misclassification on investors (e.g., Sharpe, 1992; Brown \& Goetzmann, 1997; Dibartolomeo \& Witkowski, 1997; Chan, Chen, \& Lakonishok, 2002; Cooper, Gulen, \& Rau, 2005; Sensoy 2009; Boyer, 2011; and Cao, Iliev, \& Velthuis, 2017), and the effects of style investing on the cross-section of stock returns and on return predictability (e.g., Barberis \& Shleifer, 2003; Teo \& Woo, 2004; Kumar, 2009; and Wahal \& Yavuz, 2013).

Note 3. Lakonishok et al. (1994) argue that growth investors are optimistic in their extrapolations and follow trends in their trading, while value investors are contrarian traders who exploit this suboptimal behavior. Using various strategies to identify expectation errors, La Porta (1996), La Porta et al. (1997), Piotroski and So (2012), and Walkshausl (2017) provide supporting evidence, but Dechow and Sloan (1997); and Doukas, Kim, and Pantzalis (2002) report conflicting results. Using surveys, Shefrin and Statman (1995, 2003); and Shefrin (2015) find that style investors misjudge the risk-return tradeoff of their investments, with small-cap and value investors expecting returns too low (being pessimistic) and large-cap and growth investors expecting returns too high (being optimistic). Using trading accounts, Blackburn et al. (2014) show that value investors tend towards contrarian trading and growth investors tend toward momentum trading.

Note 4. CK investigate the finite sample properties of SDF alphas estimated with a similar system of moments and find that inferences are generally robust to finite sample issues. They also show that $t$-statistics for their alphas are similar when using no lag or four lags. The choice of two lags is meant to control for the small but significant serial correlation in the returns of some funds (that might invest in thinly traded assets).

Note 5. Using best clientele alphas, Chrétien and Kammoun (2018) also examine the expected disagreement with Fama-French alphas and find a similar result. Specifically, they get a mean alpha of $\alpha_{S, F F}+0.323 \%$ for the best clienteles.

Note 6. Of course, other sets of passive portfolios could be relevant, but existing evidence suggests that our results should not be qualitatively affected by this choice. For example, CK examine the sensitivity of their performance bound results to three sets of passive portfolios and find robustness. FL also find that their results on investor disagreement are robust to changes of benchmark returns.

Note 7. Specifically, we identify US equity funds by policy codes CS and Lipper objective codes EIEI, EMN, LCCE, LCGE, LCVE, MATC, MATD, MATH, MCCE, MCGE, MCVE, MLCE, MLGE, MLVE, SCCE, SCGE or SCVE, and keep the funds only if they hold between $80 \%$ and $105 \%$ in common stocks. We exclude index funds identified by the Lipper objective codes SP and SPSP or with a name that includes the word "index", and funds not opened to investors by consulting the variable "open to investors".

Note 8. Barras et al. (2010) and CK find that their performance results are similar when using a 36-month requirement instead of a 60 -month requirement.

Note 9. The Fama-French SDF is a linear function of the market, SMB and HML factors available on Kenneth R. French's website. For each fund, we estimate jointly the parameters of the Fama-French SDF and the alpha by using GMM with a just identified system. Specifically, we estimate the four parameters of the Fama-French SDF by requiring the SDF to correctly price the one-month Treasury bill returns and the three Fama-French factors, and the alpha by using a moment similar to equation (19), but with the Fama-French SDF replacing the style SDF.

Note 10. The Morningstar fund classification codes are not available in the CRSP mutual fund database.

Note 11. Some papers, like Pástor and Stambaugh (2002), use instead all three sources of codes but subjectively assign various codes to their broad investment objectives. In an attempt to extend our sample period to 1984, we 
examine a style classification based on the Lipper, Wiesenberger and Strategic Insight codes, prioritized in that order. We find that the codes from the latter two sources are not useful because of the difficulty to assign them to our categories. In particular, they do not identify more value funds, and only convincingly identify 20 new small-cap growth funds.

Note 12. In 2015, their website mentions that: "Lipper's benchmarking and classifications are widely recognized as the industry standard by asset managers, fund companies and financial intermediaries. Our reliable fund data, fund awards designations and ratings information provide valued insight to advisors, media and individual investors."

Note 13. Specifically, these Lipper codes are EIEI, LCCE, MCCE, MCGE, MCVE, MLCE, MLGE, MLVE and SCCE.

Note 14. The Other funds have Lipper codes EMN, MATC, MATD and MATH.

Note 15 . When the threshold is $25 \%$, it is possible for a fund to end up in more than one corner style. To eliminate this possibility, we assign funds to the LCG, SCG, LCV and SCV styles in this predetermined order and remove them from consideration once assigned. As a robustness check, we verify the importance of the ordering for the style classification and find it has little effect as only one fund switches style.

Note 16. The market portfolio is the CRSP value-weighted index. Consumption growth is the growth in aggregate per capita consumption, using seasonally-adjusted personal consumption expenditures on non-durables and services, adjusted by their respective deflator, and divided by the resident population. Labor income growth is measured, following Jagannathan and Wang (1996) and others, as a two-month moving average in per capita labor income, with labor income being the difference between total personal income and dividend income. The data to construct consumption growth and labor income growth are from the Federal Reserve Bulletin (FRED). Change in macroeconomic uncertainty is the change in the one-month-ahead macro uncertainty variable of Jurado, Ludvigson, and Ng (2015) taken from Sydney C. Ludvigson's website. The results are qualitatively similar if we use instead their twelve-month-ahead macro uncertainty variable. Investor sentiment and its change are computed from the "sentiment aligned" measure of Huang, Jiang, Tu, and Zhou (2015) available on Guofu Zhou's website. The results are qualitatively similar if we use the sentiment measure of Baker and Wurgler (2006, 2007).

Note 17. Examples of related SDF decompositions are in Bansal and Viswanathan (1993), Chapman (1997), Dittmar (2002) and Rosenberg and Engle (2002). For a detailed discussion and relevant literature on interpreting SDF decompositions from the rational and behavioral perspectives, see Shefrin (2008, 2009). The fitted results for the narrow style SDFs are not illustrated, but we generally find that the LCV SDF is similar to the Value SDF, the LCG SDF is similar to the Large SDF, and the SCG and SCV SDFs are similar to the Small SDF.

Note 18. Notice that the SDFs should increase with change in macroeconomic uncertainty for risk aversion. For a more comparable graph, figure $2 \mathrm{~d}$ uses a reverse order scale so that the variable is ordered from "bad" to "good" states.

Note 19. Our discussion is related to the study of Bondarenko (2003). In a general environment, he provides an analysis of the implications of potentially biased beliefs for SDFs. One of his findings is that there is an equivalence relationship between preferences and beliefs, so that the same prices can result from either risk aversion or biased beliefs (or some combination of the two). An econometrician cannot distinguish between both possibilities.

\section{Copyrights}

Copyright for this article is retained by the author(s), with first publication rights granted to the journal.

This is an open-access article distributed under the terms and conditions of the Creative Commons Attribution license (http://creativecommons.org/licenses/by/4.0/). 